\title{
Passive acoustic monitoring on the North Atlantic right whale calving grounds
}

\author{
Melissa S. Soldevilla ${ }^{1, *}$, Aaron N. Rice ${ }^{2}$, Christopher W. Clark ${ }^{2}$, Lance P. Garrison ${ }^{1}$ \\ ${ }^{1}$ Southeast Fisheries Science Center, NOAA, 75 Virginia Beach Drive, Miami, FL 33149, USA \\ ${ }^{2}$ Bioacoustics Research Program, Cornell Lab of Ornithology, Cornell University, \\ 159 Sapsucker Woods Road, Ithaca, NY 14850, USA
}

\begin{abstract}
North Atlantic right whales Eubalaena glacialis calve during winter off Florida and Georgia, USA, a region of high shipping traffic, and ship-strike risk is a concern. Passive acoustic monitoring (PAM) of right whales on their foraging grounds increases detection opportunities to inform mariners of right whale presence and reduce the likelihood of ship strike. This study evaluates the effectiveness of PAM on right whale calving grounds by documenting the occurrence of right whale call detections on 2 types of acoustic instruments deployed off the coasts of Savannah, GA, and Jacksonville, FL, and comparing results with visual sightings and ambient noise conditions. Over 400 right whale calling events were detected on archival marine acoustic recording units (MARUs) at 2 sites across 2 seasons, and $92 \%$ of these calling events included right whale upcalls. Daily detections on archival MARUs and near-real time Autobuoys, which automatically detect upcalls, were significantly correlated and occurred on up to $25 \%$ of days off Savannah and $46 \%$ of days off Jacksonville. Visual aerial surveys detected right whales within $20 \mathrm{~km}$ of each acoustic site on a similar proportion of days with visual survey effort (15 to 33\% off Savannah and 34 to $43 \%$ off Jacksonville). Acoustic methods enabled greater temporal effort, yielding a 2- to 10 fold increase in days with right whale detections over visual methods. Shipping noise and fish chorusing likely mask right whale call detections. However, considering the high number of right whale calling event detections by PAM during this study the results indicate that this is an effective method to augment detection of right whales in this environment, especially at night when they cannot be seen.
\end{abstract}

KEY WORDS: Marine mammal · Monitoring · Distribution $\cdot$ Eubalaena glacialis $\cdot$ Passive acoustic $\cdot$ Ambient noise Resale or republication not permitted without written consent of the publisher

\section{INTRODUCTION}

The North Atlantic right whale Eubalaena glacialis is one of the most endangered of cetacean species, with an estimated 400 individuals remaining (Waring et al. 2012). Each winter, a portion of the population migrates south to their only known calving ground off Florida and Georgia (Knowlton \& Kraus 2001, Kraus et al. 2005, Waring et al. 2012). From November through May, pregnant females, mother-calf pairs, juveniles and, to a lesser extent, non-calving adult females and adult males can be found on the southeast calving grounds (Kraus et al. 1986). This area has been designated as critical habitat under the Endangered Species Act (50 CFR Part 226, Federal Register 59:28793). Ship strikes are the leading cause of anthropogenic mortality for this species (Knowlton \& Kraus 2001), and this critical calving habitat overlaps with several major shipping lanes, including 5 major shipping ports (Ward-Geiger et al. 2005). Ship-strike mitigation efforts are essential in the southeast calving grounds where reproductively active females and a large number of other right whales spend their winters. 
Fixed passive acoustic monitoring (PAM) surveys are increasingly being used for marine mammal monitoring, management, and mitigation as they can detect vocalizing cetaceans in conditions that are challenging for visual surveys, including nighttime and rough sea conditions, are relatively inexpensive, and can be deployed over long time periods (Mellinger et al. 2007b, Van Parijs et al. 2009). Thus, for the conservation and management of these protected species, PAM provides a cost-effective and data-rich survey methodology which can be used in combination with other survey methods. Over the past decade, passive acoustic methods have been successfully used for monitoring and mitigation of North Atlantic right whales on their northeast foraging grounds, and recent efforts expand this work to the southeast calving grounds. In fall 2009, PAM with near real-time reporting of whale presence was implemented on the southeast calving grounds to increase the likelihood of detecting right whales (e.g. Clark et al. 2005, Van Parijs et al. 2009, Spaulding et al. 2010). Archival PAM has been used to effectively detect and monitor temporal changes in occurrence of North Atlantic right whales and North Pacific right whales Eubalaena japonica on their foraging grounds (Mellinger et al. 2004, 2007a, 2011, Munger et al. 2008, Morano et al. 2012, Mussoline et al. 2012), and near real-time monitoring and reporting have been used effectively for ship strike mitigation on the North Atlantic right whale foraging grounds (Spaulding et al. 2010).

While archival and near real-time PAM methods have proven effective on the northeast foraging grounds, their effectiveness on the southeast calving grounds remains an open question. A variety of factors influence the effectiveness of passive acoustic methods, including animal calling behavior, automated detector capabilities, ambient noise levels, and sound propagation conditions (Mellinger et al. 2007b, Stafford et al. 2007, Clark et al. 2009, 2010, Holt et al. 2011, Marques et al. 2011). Most studies of North Atlantic right whale calling behavior, including calling rates, call type usage, and source levels, have focused on whales on the foraging grounds, and less is known about calling behavior on the calving grounds (Parks et al. 2005, 2009, 2011, 2012, Parks \& Tyack 2005). Automated detectors have been developed for North Atlantic right whale upcalls (Gillespie 2004, Urazghildiiev \& Clark 2006, 2007, Urazghildiiev et al. 2009, Dugan et al. 2010a,b); these contact calls are frequently produced on the foraging grounds (Clark et al. 2010), but it is not known how frequently they are used on the calving grounds. North Atlantic right whale calving habitat occupies shelf waters, typically < $25 \mathrm{~m}$ depth (Garrison 2007, Keller et al. 2012), which are shallower than on the foraging grounds. Shallow shelf environments exhibit high variability in ambient noise levels and sound propagation conditions over a variety of temporal scales (Urick et al. 1969). Shallow water ambient noise conditions are affected by numerous noise sources, including wind and waves, biological noise from fish and other animals, and near and distant ship passings and industrial noise (Urick \& Gaunaurd 1972, Zakarauskas 1986, McKenna et al. 2012). Therefore, to use passive acoustic methods for monitoring right whales in the shallow water environment of the southeast calving grounds, it is important to quantify call type occurrence and the effects of ambient noise on right whale call detectability in this region.

This study seeks to evaluate what factors influence the effectiveness of PAM for mitigation of ship strikes with North Atlantic right whales on the calving grounds by examining temporal patterns in right whale call detections from fixed acoustic instruments and the influence of temporal variation in ambient noise on call detectability. Continuously recording archival marine acoustic recording units (MARUs) were deployed in conjunction with near real-time automatic detection buoys (Autobuoys) at 2 sites on the southeast calving grounds over the 2009-2010 and 2010-2011 calving seasons. We describe temporal and spatial variability in archival call detections on diel to annual scales and compare these to near real-time detections and aerial survey sightings to aid in interpretation of environmental influences on detectability. Temporal variability in ambient noise is described, and the effects of physical, biological, and anthropogenic noise sources on call detectability are evaluated. The implications for use of passive acoustics as a mitigation tool for North Atlantic right whales on the calving grounds are discussed.

\section{MATERIALS AND METHODS}

\section{Instrumentation and data collection}

During the 2009-2010 and 2010-2011 calving seasons, a PAM system with both archival recording (Calupca et al. 2000) and near real-time reporting capabilities (Spaulding et al. 2010) was deployed in $17 \mathrm{~m}$ depth waters at 2 sites on the North Atlantic right whale calving grounds, off the coasts of Savannah, GA, and Jacksonville, FL, USA (Fig. 1, Table 1). The Savannah site was chosen as it is just north of the critical calving habitat with close proximity to a ship- 
ping lane, while the Jacksonville site was chosen for its location in the center of the calving habitat and close proximity to a major shipping lane. Each acoustic monitoring system consisted of (1) an Autobuoy with the capability to detect and notify a landbased station of the occurrence of vocalizing North Atlantic right whales in the vicinity of each buoy in near real time (Spaulding et al. 2010) and (2) an archival MARU (e.g. Clark et al. 2002, Clark \& Clapham 2004) that provided continuous recordings over the deployment period. For these specific deployments, the Autobuoys were designed to automatically detect right whale upcalls (Fig. 2A) (Clark 1982, Parks \& Tyack 2005) as they are the most commonly occurring call, are produced by all age and sex classes (Parks et al. 2011), and are readily detected by automated detectors (Gillespie 2004). To extend deployment durations, Autobuoys save and transmit only a subset of the best upcall detections. In addition to upcalls, right whales also produce a variety of other call types (Fig 2B-E) including downcalls, screams (also described as high calls), moans, variable calls, and gunshots (Clark 1983, Matthews et al. 2001, Parks \& Clark 2007, Parks et al. 2011) and the frequency of usage of these different call types on the calving grounds is unknown. The continuously recording MARUs are able to capture all call types as well as provide data on ambient noise conditions to evaluate the effectiveness of the Autobuoy for right whale ship-strike mitigation in this region. However, automated call detectors, such as those used by the Autobuoy, are only available for upcalls, so other call types must be manually selected from archival MARU recordings.

Each MARU, an archival digital audio recording system containing batteries, computer electronics and internal memory in a $43 \mathrm{~cm}$ glass sphere, was deployed hard-mounted

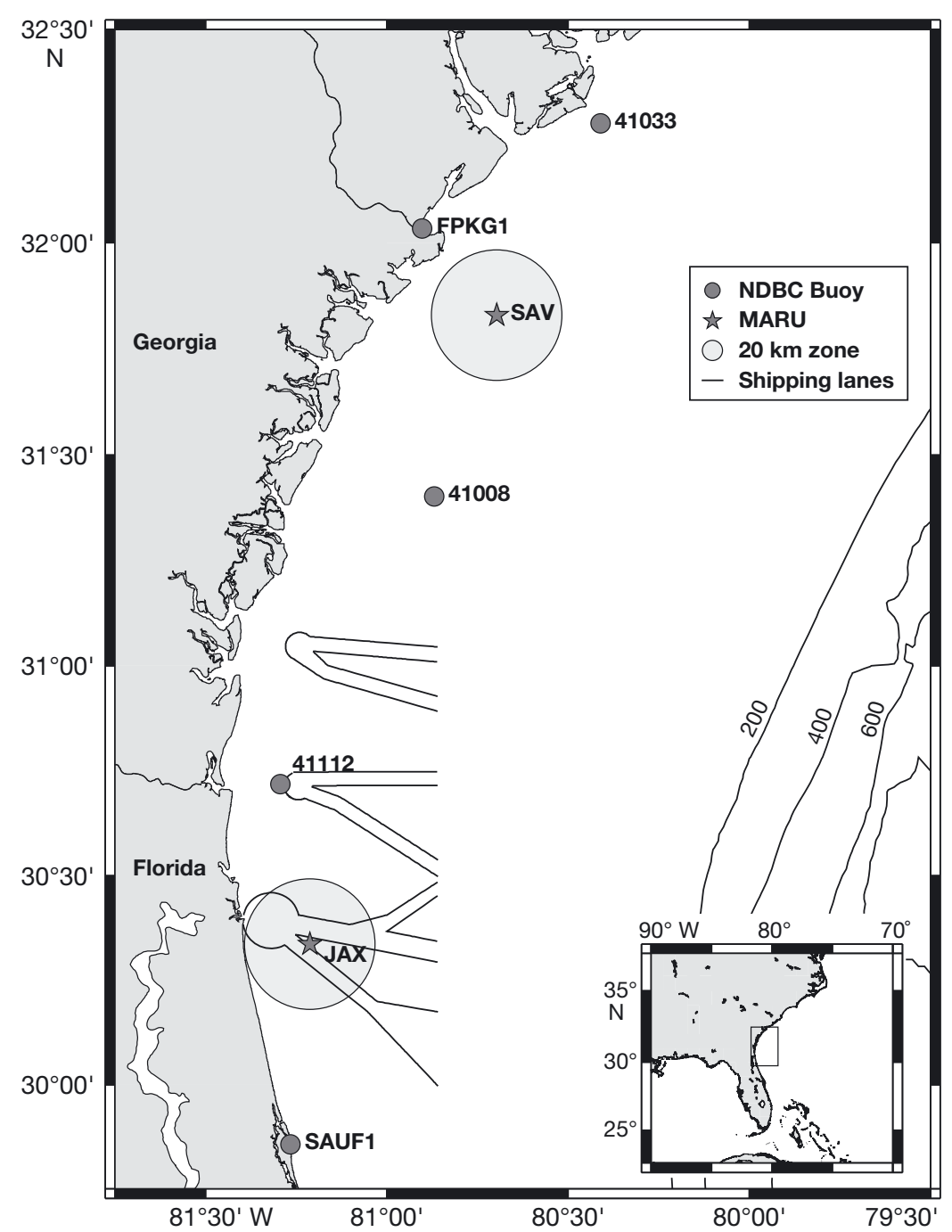

Fig. 1. Location of Autobuoys and marine acoustic recording units (MARUs) ( $\star$ ) deployed off Savannah, Georgia (SAV) and Jacksonville, Florida (JAX), and National Data Buoy Center (NDBC) buoys (O). Autobuoys and MARUs were deployed from November 17, 2009 to June 1, 2010 and from Janunary 15 to June 4, 2011. Designated shipping lanes off Florida and Georgia and $20 \mathrm{~km}$ zones around MARUs are also shown

Table 1. Autobuoy and marine acoustic recording unit (MARU) deployment details. Dates are shown as mm/dd/yyyy

\begin{tabular}{|lcc|}
\hline Site name & Savannah & Jacksonville \\
\hline Latitude & $31.829^{\circ} \mathrm{N}$ & $30.337^{\circ} \mathrm{N}$ \\
Longitude & $80.697^{\circ} \mathrm{W}$ & $81.212^{\circ} \mathrm{W}$ \\
Depth & $17.3 \mathrm{~m}$ & $16.7 \mathrm{~m}$ \\
Season 1 Start & $11 / 18 / 200922: 04 \mathrm{~h}$ & $11 / 19 / 200910: 17 \mathrm{~h}$ \\
Season 1 End & $03 / 16 / 201019: 34 \mathrm{~h}$ & $06 / 04 / 201007: 45 \mathrm{~h}$ \\
Season 2 Start & $01 / 12 / 201116: 58 \mathrm{~h}$ & $01 / 13 / 201108: 03 \mathrm{~h}$ \\
Season 2 End & $05 / 25 / 201117: 29 \mathrm{~h}$ & $05 / 26 / 201105: 46 \mathrm{~h}$ \\
\hline
\end{tabular}



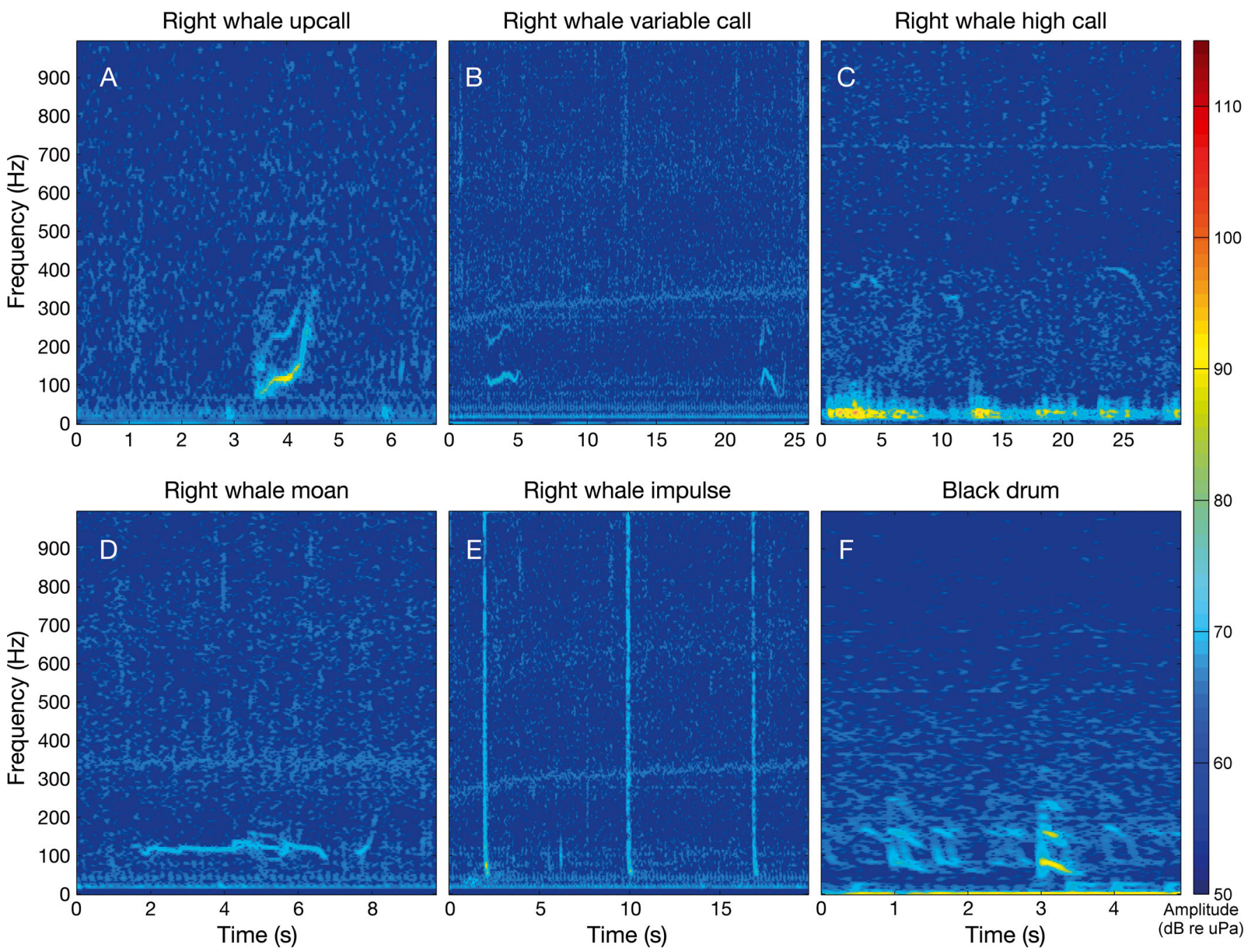

Fig. 2. Example spectrograms of right whale call types detected on the southeast calving grounds and (panel F) calls of the fish species black drum Pogonias cromis. (A) Right whale upcalls are frequency modulated tonal calls that generally increase in frequency. (B) Variable calls are also frequency modulated tonal calls but have multiple inflection points. (C) High calls are frequency modulated tonal calls ranging between 300 and $600 \mathrm{~Hz}$. (D) Moans are generally longer duration tonal calls that have little frequency modulation. (E) Impulsive sounds are distinctive broadband impulses with a slight downsweep around $50 \mathrm{~Hz}$, possibly due to modal propagation. These may be the same as gunshots recorded on the feeding grounds or may be flipper or tail slaps on the water surface. (F) Black drum drumming calls are 86 to $80 \mathrm{~Hz}$ downsweeps that typically occur in choruses. During intense periods, individual calls cannot be distinguished. Spectrograms were calculated with (A) 300 or (B to F) 512 point

Discrete Fourier Transforms (DFTs) with Hann windows and $95 \%$ overlap. Note different time scales of spectrograms

to the Autobuoy mooring frame. A hydrophone mounted outside the sphere acquires sounds that are recorded and stored in a binary digital audio format on the internal hard disk. After recovery, the MARU data are extracted, converted into audio files, and stored on removable hard drives for analysis. For all deployments, MARUs recorded continuously at 12 bits and $2000 \mathrm{~Hz}$ sampling rate, yielding a 1 to $1000 \mathrm{~Hz}$ bandwidth. The MARU system included an HTI-94-SSQ hydrophone (High Tech) $(-168 \mathrm{~dB}$ re $1 \mathrm{~V} \mu \mathrm{Pa}^{-1}$ sensitivity between 2 and $30 \mathrm{kHz}$ ) and a
$23.5 \mathrm{~dB}$ gain pre-amplifier which applied a $10 \mathrm{~Hz}$ high-pass filter to reduce internal electrical interference and an $800 \mathrm{~Hz}$ low-pass filter to prevent aliasing. The A/D (analog to digital) converter had a sensitivity of $10^{3}$ bit $\mathrm{V}^{-1}$, and an additional gain of $1 / 2048$ was added during data storage to hard drive. This yielded a total system sensitivity of $-151.2 \mathrm{~dB}$ re $1 \mu \mathrm{Pa}$ with a flat frequency response $( \pm 1 \mathrm{~dB})$ between 15 and $585 \mathrm{~Hz}$ (Parks et al. 2009). This frequency range encompasses the fundamental frequency of most right whale calls. 

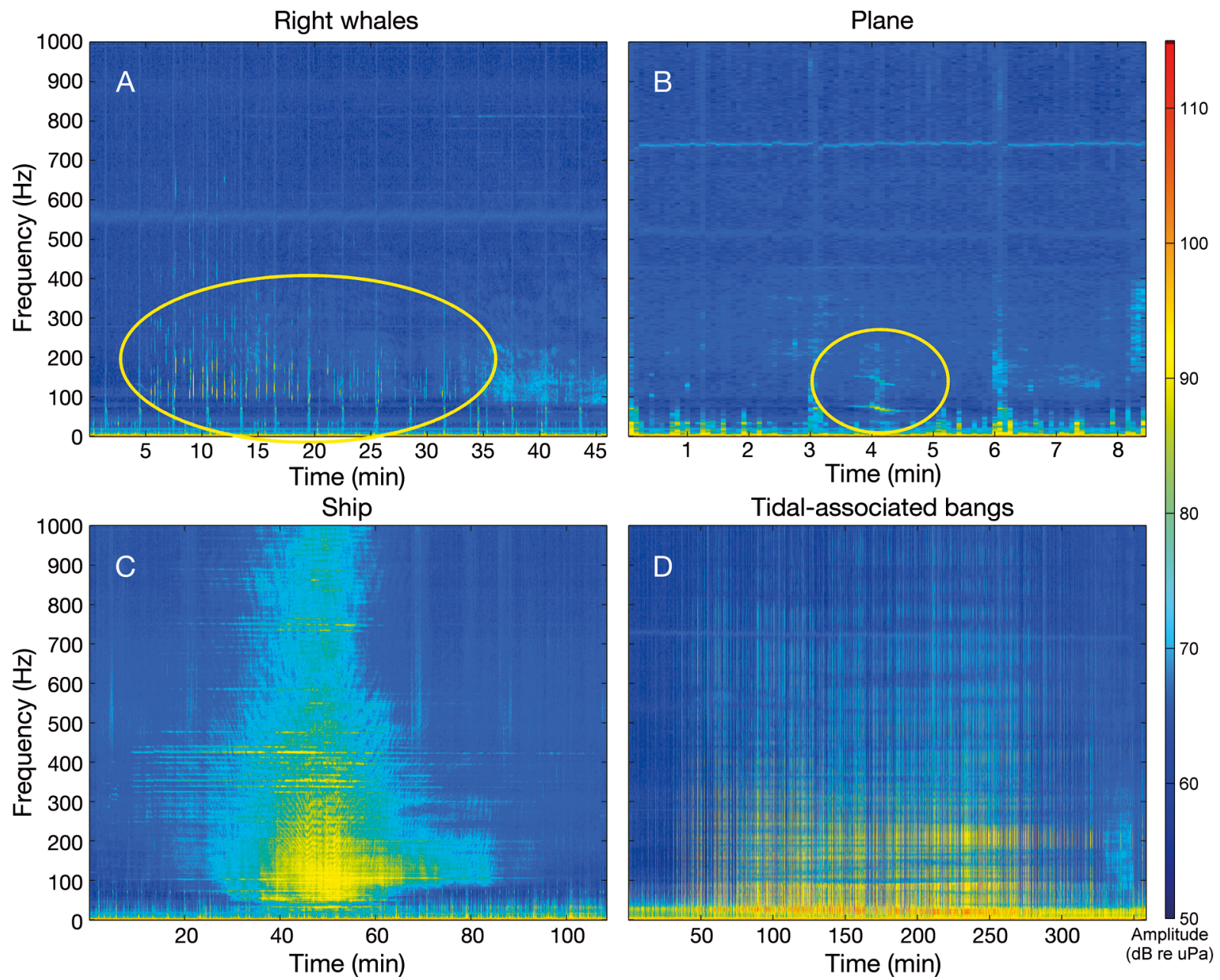

Fig. 3. Long-term spectral averages (LTSAs) for the 4 distinct acoustic event types that were logged during acoustic event analysis of MARU deployment data: (A) right whale calling bout, (B) airplane overpass, (C) ship passings, and (D) tidal-associated banging. LTSAs were calculated in MATLAB with the Welch periodogram algorithm (500 point DFT, 0\% overlap, Hann window) and have $2 \mathrm{~Hz} \times 5$ s resolution. Note different time scales

\section{Acoustic analysis}

Acoustic data were analyzed with a custom software program, TRITON (Wiggins et al. 2010), developed in MATLAB (The MathWorks). Raw acoustic data were converted to WAV format. A total of $586 \mathrm{~d}$ of recordings were collected across the 4 MARU deployments, which are impractical to analyze manually in original form. Therefore, these data were compressed for visual overview by creating long-term spectral averages (LTSAs) (Wiggins \& Hildebrand 2007) from the WAV files. LTSAs are effectively compressed spectrograms created using the Welch algorithm (Welch 1967) by coherently averaging 20 spectra created from 500point, $0 \%$-overlapped, Hann-windowed data and displaying these averaged spectra sequentially over time. The resulting LTSAs had resolutions of $2 \mathrm{~Hz}$ and
$5 \mathrm{~s}$ in frequency and time, respectively. This resolution LTSA allows right whale calling bouts (identified by the occurrence of any of the right whale call types), ship passings, and other acoustic phenomena (Fig. 3) to be easily distinguished from background noise (e.g. Wiggins \& Hildebrand 2007) while TRITON allows one to easily move between LTSAs and associated WAV files to confirm acoustic identifications from spectrograms, as needed. By visually examining 30 min long LTSA segments, the start and end times of right whale calling bouts and other frequently occurring acoustic events were located and logged. Right whale calls typically occur in bouts (Parks et al. 2011), making them easy to distinguish in the LTSA domain. Individual calls can be distinguished, particularly those with good signal to noise ratio (SNR), but occurrences of only a few, low SNR calls are likely to be 
missed by this method. Other logged acoustic events included airplane and ship passings and a 'banging' noise of unidentified source that is likely related to self-noise of the recording unit anchoring system. Airplane passings, which generally fell within the 80 to $200 \mathrm{~Hz}$ frequency range and lasted approximately 30 to $90 \mathrm{~s}$, were investigated for comparison with detectability of right whale calls, under the assumptions that their occurrence is consistent over time and that sound propagation variability and ambient noise masking would similarly affect LTSA detection of both airplane passing and right whale calling events. Ship passings and banging noises were investigated for their potential to obscure the detection of right whale calls. The banging noise was a broadband impulsive sound with energy extending across the sampled frequency range with maximum energy below $100 \mathrm{~Hz}$, including resonant frequency peaks around $30 \mathrm{~Hz}$ and associated harmonics (e.g. 60, $90 \mathrm{~Hz}$ and above). While individual pulses were $<0.1 \mathrm{~s}$ in duration, consecutive pulses occurred in bouts of approximately 6 to $8 \mathrm{~h}$ duration and could potentially obscure detection of right whale calls over this entire period. For all 4 acoustic event types, start and end times were used to calculate hourly and daily occurrence as minutes present per hour and minutes present per day, respectively. The LTSA manual analysis was chosen over an automated upcall detector analysis to ensure all right whale call types were evaluated and to allow evaluation of other noise sources which may influence call detectability. In this dataset, right whale calling bouts are unlikely to be misidentified as humpback calling bouts, as commonly occurs on the northeast foraging grounds, since all right whale calling bouts were visually identified and checked by a trained acoustician.

Longer term hourly means and variances of ambient noise levels were calculated from the short-time (5 s) LTSAs for a large-scale view of ambient noise variability across deployments and sites. Fish chorusing events were observed during this analysis, and the seasonal and diel timing of black drum drumming choruses (Fig. 2F) were examined by plotting ambient noise levels in the $150 \mathrm{~Hz}$ frequency band (the drumming 2nd harmonic which occurs in the right whale call frequency range) as a function of date and time of day to evaluate the potential of these biological noise sources to obscure right whale calling bouts. To examine the influence of ambient noise levels on the ability to detect right whale calls in the visual LTSA analysis, the daily mean ambient noise levels at $150 \mathrm{~Hz}$ were compared to the daily sum of minutes with acoustic event detections. Data contain- ing the banging noise, thought to be system noise, were removed from the ambient noise analysis.

\section{Temporal analysis of acoustic events}

Following the LTSA acoustic event analysis, the presence and absence of event detections were tallied for each minute of data examined, and the resulting data were aggregated hourly and daily to show the number of minutes in each hour and each day, respectively, during which an acoustic event occurred. As right whales migrate into the region seasonally, the first and last detection at each site and the peak in occurrence are described. To examine diel variability in acoustic event presence, hour bins were assigned to day and night photoperiods based on sunrise and sunset data obtained for each site from the US Naval Observatory (2011). Day and night were defined as the periods between nautical twilight, when the sun altitude was at $-12^{\circ}$ from the horizon. Seasonal differences in photoperiod durations were accounted for by reporting the mean minutes per hour with acoustic events present for each daily photoperiod. To test for the effects of fish chorusing on acoustic event detectability, data from each site and deployment season were assigned to either pre-drum chorus or drum chorus categories. The main effects and interaction terms of photoperiod, deployment season, site, and drum chorusing were tested for differences in mean minutes per hour with acoustic events present using a 4-factor ANOVA test with all factors set as fixed effects. Years and sites were not randomly selected; these results cannot be extrapolated to other sites or times. Sum of squares Type III calculations were used to handle the unbalanced design. In cases where factors were significant at alpha levels of 0.05, TukeyKramer post-hoc tests were used to determine which factor levels were significantly different (Zar 1999, Garson 2008). Similar 4-factor ANOVA and TukeyKramer post-hoc tests were run to test for differences in $150 \mathrm{~Hz}$ mean ambient noise levels.

\section{Autobuoy - MARU comparison}

To quantify the effectiveness of the near-real time automated detections for ship-strike mitigation, detections on the co-located MARUs and Autobuoys were compared. The 2 systems sample on different scales; to account for this, both the daily presence or absence of call detections and proportional measures of daily call occurrence were compared between sys- 
tems. The Autobuoy detection system (Spaulding et al. 2010) processed acoustic data, detected, and recorded potential upcalls as 2 -second audio files in memory on the buoy. These detections were scored from 1 to 10 (10 has the highest likelihood of being a right whale upcall). In 2009-2010, detection candidates were saved if their scores exceeded 5 , while this threshold was increased to 8 in 2010-2011. The system then uploaded the 10 highest quality detection candidates within a $6 \mathrm{~h}$ window to a shore side server. Upcall candidates were verified by expert analysts at Cornell University's Bioacoustics Research Program and made available through a secure web interface. On the other hand, MARUs collected data continuously and right whale call detections were aggregated by event as minutes per hour with calls present. For comparisons across instruments within each site and calving season, all confirmed Autobuoy right whale upcall detections with scores exceeding 8 were aggregated into daily time bins. Autobuoy call detections per day were compared to MARU minutes per day with right whale call detections from the LTSA event analysis. While the 2 acoustic detection methods have a number of differences (calling metric, call types included, Autobuoy cap on maximum number of detections), a high degree of correlation can still be expected between them if both methods are effective for detecting calling right whales. Simple linear correlation coefficients were calculated in MATLAB to determine how closely these 2 detection methods correspond at daily scales (Zar 1999).

\section{Comparison of MARU and aerial survey sightings}

To quantify the effectiveness of acoustic methods for ship-strike mitigation, the daily MARU call bout detections were compared to visual sightings conducted by the Southeast United States (SEUS) aerial survey teams. North Atlantic right whale sightings data from the 2009-2010 and 2010-2011 SEUS surveys included data from 4 regions: South Carolina Georgia (SCGA), Northern Early Warning System (NEWS), Central Early Warning System (CEWS), and Southern Early Warning System (SEWS) regions (Jackson \& Pitchford 2010, Naessig \& Taylor 2010, 2011, Schulte \& Taylor 2010, 2011, Taylor et al. 2010, Jackson et al. 2011a,b). In general, SEUS aerial surveys follow standard linetransect procedures and are flown on all good weather days between December 1 and March 31 of each calving season (November 15 to April 15 for SCGA) to aid in right whale ship-strike mitigation and population monitoring. The surveys are designed with transect lines that are approximately $55 \mathrm{~km}$ in length, with lines separated by $5.5 \mathrm{~km}$. Observers scan out to $3.7 \mathrm{~km}$ on either side, resulting in overlapping strips. The surveys are conducted in sea states 3 or less. Planes are flown at an altitude of $305 \mathrm{~m}$ and an average speed over ground of $185 \mathrm{~km} \mathrm{~h}^{-1}$. The goal of these surveys is to detect, locate, and count right whales and obtain high quality photographs of each whale for photo identification, and to report locations of sightings to mariners transiting the critical habitat region. For sightings identified as right whales, the airplane breaks from the trackline to obtain an accurate location and take photographs for whale identification. The airplane returns to the trackline departure point when photographic effort is complete.

In 2009-2010, the SCGA, NEWS, CEWS, and SEWS teams flew 44, 37, 69, and $60 \mathrm{~d}$, respectively, while in 2010-2011, they flew $42,35,51$, and $42 \mathrm{~d}$ respectively. The SCGA region is made up of 3 sections, with each section surveyed on approximately one-third of the total survey days. Temporally, effort was lower across all 4 regions in 2010-2011 than 2009-2010 due to poorer weather conditions, with the 2 southern zones affected more. Spatially, more effort was expended in the CEWS and SEWS survey regions compared to the NEWS and SCGA regions (Jackson \& Pitchford 2010, Naessig \& Taylor 2010, 2011, Schulte \& Taylor 2010, 2011, Taylor et al. 2010, Jackson et al. 2011a,b).

Visual aerial line-transect surveys and fixed acoustic point surveys are quite different platforms with different sampling biases. Aerial surveys rapidly cover a large spatial area in a short period of time, with a given parcel of water sampled for only a minute or so, while fixed acoustic surveys continuously sample a small spatial area over a long time period. The probability of detecting a right whale by aerial survey is a function of availability (the whale being at the surface while the plane is passing over) and sightability (whale behavior, distance from the ship, environmental conditions such as glare and sea state) (Hain et al. 1999). Given these considerations, during the brief snapshot of time an airplane is over an area, the probability of detecting a right whale that is present in the area through these methods is 0.33 (Hain et al. 1999). This probability is increased slightly by closely spaced transect lines such as those conducted in the SEUS. The probability of detecting a right whale through acoustic methods is a combination of availability (the whale calling) and detectability (distance from receiver, ambient noise conditions) (Clark et al. 2010). These probabilities are unknown for the SEUS area, but it is suspected that if a whale is within the detection area, and it calls once a day, it will be detected. 
To compare visual aerial line-transect and acoustic point surveys, a simplistic approach was taken. To account for the spatial-temporal mismatch, daily presence or absence was compared across platforms, and aerial survey sightings were limited to those within a $20 \mathrm{~km}$ radius around each MARU. While the MARU detection distances are probably significantly less than $20 \mathrm{~km}$, this radius was chosen to account for animal movements over the course of a day. Given the close spacing of transect lines and $160 \mathrm{~km} \mathrm{~h}^{-1}$ air speed, the aerial surveys sampled up to 8 lines within this disk and covered the area for up to 15 min per pass. Only days with survey effort in the SCGA southern section and days with CEWS or SEWS effort were considered when examining aerial survey effort for these regions. Total days with right whale presence per season and proportion of days with detections with respect to days with effort were compared across methods.

\section{Sea surface temperature}

To examine large-scale differences in temperature on the right whale calving grounds between years, the average daily temperature across the region was obtained from 5 NOAA National Data Buoy Center (NDBC) buoys located within the calving grounds. Hourly and semi-hourly time series of sea surface temperature (SST) were obtained from the 3 nearest (30 to $57 \mathrm{~km}$ away) buoys to the Savannah MARU sites and the 2 nearest (43 to $54 \mathrm{~km}$ away) buoys to the Jacksonville MARU site (Fig. 1) from the NDBC (2012) website. All stations sampled SST hourly, except for Buoy 41112 which sampled every half hour. For consistency, this time-series was downsampled to an hourly sample rate by taking the first sample of the hour. The regional daily mean temperature and variance were calculated by combining data from the 5 buoys.

\section{RESULTS}

\section{MARUs: data quality}

The total number of days of data recordings available per MARU deployment ranged between 119 and 198 d (Tables 1 \& 2). Data from the 2009-2010 and 2010-2011 seasons at Jacksonville and the 2010-2011 season at Savannah were of good quality, while the 2009-2010 data from Savannah suffered from intermittent recording failures. Good quality data for this deployment are available up to December 12, 2009, after which point few data recordings were made through early to mid-January 2010. Data recording duration increased through February and began to drop off again in March, failing completely on March 16, 2010. Limited data analyses are presented for this dataset. When these data are included in comparative analyses with other datasets, all data are normalized by the duration of the available recordings per hour.

Table 2. Short-time long-term spectral average (LTSA) analysis of data from MARU deployments collecting data on right whale occurrence. Number of events represents a minimum number as overlapping events were treated as 1 occurrence. Shipping events were most affected by this lumping. 'Bangs' refers to tidal-associated banging noise. 'Bad data' indicates intermittent data loss during the Savannah 2009-2010 deployment. Values in parentheses show percentage of days or hours present. The final column shows the total numbers of days and hours recorded. (-) not applicable

\begin{tabular}{|c|c|c|c|c|c|c|}
\hline & Right whales & Plane & Ship & Bangs & Bad data & Recordings \\
\hline \multicolumn{7}{|c|}{ Jacksonville 2009-2010 } \\
\hline No. of events & 131 & 652 & 1180 & 400 & - & - \\
\hline Days present (\%) & $51(25.8)$ & $166(83.8)$ & $198(100.0)$ & 189 (95.5) & - & 198 \\
\hline Hours present $(\%)$ & $114.6(2.4)$ & $29.7(0.6)$ & $3492.9(73.9)$ & $1724.5(36.5)$ & - & 4725.4 \\
\hline \multicolumn{7}{|c|}{ Jacksonville 2010-2011 } \\
\hline No. of events & 217 & 322 & 1297 & 86 & - & - \\
\hline Days present (\%) & $35(26.1)$ & $99(73.9)$ & $134(100.0)$ & $55(41.0)$ & - & 134 \\
\hline Hours present $(\%)$ & $156.7(4.9)$ & $12.9(0.4)$ & $1855.3(58.1)$ & $81.2(2.5)$ & - & 3196.0 \\
\hline \multicolumn{7}{|l|}{ Savannah 2009-2010 } \\
\hline No. of events & 70 & 408 & 599 & 418 & 7108 & - \\
\hline Days present (\%) & $26(21.8)$ & $82(68.9)$ & $112(94.1)$ & $116(97.5)$ & $102(85.7)$ & 119 \\
\hline Hours present $(\%)$ & $18.8(0.7)$ & $18.1(0.6)$ & $523.0(18.5)$ & $1205.6(42.6)$ & $1565.8(55.3)$ & 2829.5 \\
\hline \multicolumn{7}{|l|}{ Savannah 2010-2011 } \\
\hline No. of events & 39 & 957 & 826 & 334 & - & - \\
\hline Days present (\%) & $15(11.2)$ & $126(94.0)$ & 133 (99.3) & 133 (99.3) & - & 134 \\
\hline Hours present $(\%)$ & $53.6(1.7)$ & $44.3(1.4)$ & $907.1(28.4)$ & $1274.2(39.9)$ & - & 3191.9 \\
\hline
\end{tabular}




\section{MARUs: temporal occurrence of acoustic events}

\section{Right whales}

Right whale calls, including upcalls, variable calls, moans, high calls, and impulsive sounds (Fig. 2), were detected during all MARU deployments for a total of 457 events, and events were present during 11 to $25 \%$ of recording days and 1.7 to $4.9 \%$ of recording hours per MARU deployment (Fig. 4, Table 2). Upcalls were detected in 90 to $94 \%$ of right whale events per deployment (Table 3, Fig. 5). Variable calls were also detected frequently (19 to $41 \%$ of events), while moans (0 to $36 \%$ ), high calls (6 to $15 \%$ ), and impulsive sounds ( 0 to $13 \%$ ) were detected less frequently (Table 3 ). Moans occurred more often at the Jacksonville site, while high calls were detected more often at the Savannah site. Right whale calling event durations ranged between $0.5 \mathrm{~min}$ to $12.7 \mathrm{~h}$ (Fig. 4) with a median duration of $19 \mathrm{~min}$.

During the 2009-2010 deployments, right whale calls were first detected in the first few days of recordings (on November 19 and 23, 2009 off Jacksonville and Savannah, respectively) and it is unknown whether the first migrating right whales arrived prior to MARU deployments. They were similarly detected in the first few days of the 2010-2011 season recordings (13 and 15 January, 2011 off Jacksonville and Savannah, respectively), when the instruments were deployed in mid-January, and whales had been visually detected on the calving grounds since mid-November. At Jacksonville, the last right whales were detected on 12 March, 2010 and 28 February, 2011, while at Savannah, the last right whales were detected on 11 March, 2010 and 28 February, 2011. However, recordings at Savannah in 2010 were already failing and failed completely on 16 March, 2010, so right whales may have been present beyond this time. Peaks in daily duration of call detections occur in mid February 2011 at Savannah and mid-January 2011 at Jacksonville, while calling density is more evenly distributed during 2009-2010 at Jacksonville (Fig. 4).

\section{Ships and planes}

Across seasons and sites, a total of 3902 shipping events were logged with shipping noise present in 29 to $74 \%$ of hours per deployment (Table 2, Fig. 4). This value represents a minimum number of events because ship passings frequently overlapped in time and were counted as 1 event in such instances. Across seasons and sites, ambient noise levels at $150 \mathrm{~Hz}$ in- creased by $34.2 \pm 9.2 \mathrm{~dB}$ re $\mu \mathrm{Pa}^{2} \mathrm{~Hz}^{-1}$, on average, as ships passed the instruments. At Jacksonville, minutes per day with shipping noise increased between January 1, 2010 and early April 2010 with a second peak in mid-May 2010; and similarly were high in January and February 2011 with a second peak in mid-May. Shipping noise at Savannah also peaked in minutes per day present in January and February 2011 and decreased over the remaining season (Fig. 4).

A total of 2339 plane events, with median durations of $1.6 \mathrm{~min}$, were logged and events were present in 0.4 to $1.4 \%$ of hours per deployment (Table 2, Fig. 4). These were generally evenly dispersed throughout the survey periods though with fewer in late spring, and more during the day than at night.

\section{Physical noise sources}

The broadband banging system self-noise associated with ebb tidal flows occurred during a significant proportion of the Jacksonville 2009-2010 and Savannah 2009-2010 and 2010-2011 deployments (36 to $42 \%$ of recorded hours), but only rarely during the Jacksonville 2010-2011 deployment (3\% of recorded hours) (Table 2). While individual bangs were $<1 \mathrm{~s}$ duration, consecutive banging events often lasted for 6 to $8 \mathrm{~h}$ of each $13 \mathrm{~h}$ tidal cycle. These events were more severe at the Savannah site (Fig. 4), extending across a greater percentage of the recorded frequency range and for longer durations. The difference between sites in mean minutes per hour with bangs present was $19.60 \mathrm{~min} \mathrm{~h}^{-1}(95 \%$ CI: 18.28 to $20.93 \mathrm{~min} \mathrm{~h}^{-1}$; Tukey-Kramer, $\left.\mathrm{p}<0.05\right)$. Currents are strong near the Savannah MARU (mean $22 \mathrm{~cm} \mathrm{~s}^{-1}$, with max flows up to $65 \mathrm{~cm} \mathrm{~s}^{-1}$, NDBC Buoy 41008, www.ndbc.noaa.gov) and instrument rattle is a likely source of this noise. These events increased in duration over the course of the deployment at each site (Fig. 4), with a mean difference between the first and last halves of the deployments of $9.25 \mathrm{~min} \mathrm{~h}^{-1}$ (95\% CI: 8.19 to $10.31 \mathrm{~min} \mathrm{~h}^{-1}$ ). Given the frequency range and long event durations, these noises can effectively obscure right whale calling events during LTSA event analysis, leading to reduced detectability.

\section{Fish calls}

A wide variety of fish calls, primarily produced by oyster toadfish Opsanus tau (Batrachoididae), and black drum Pogonias cromis (Sciaenidae), were detected in the MARU recordings (A. N. Rice unpubl. 

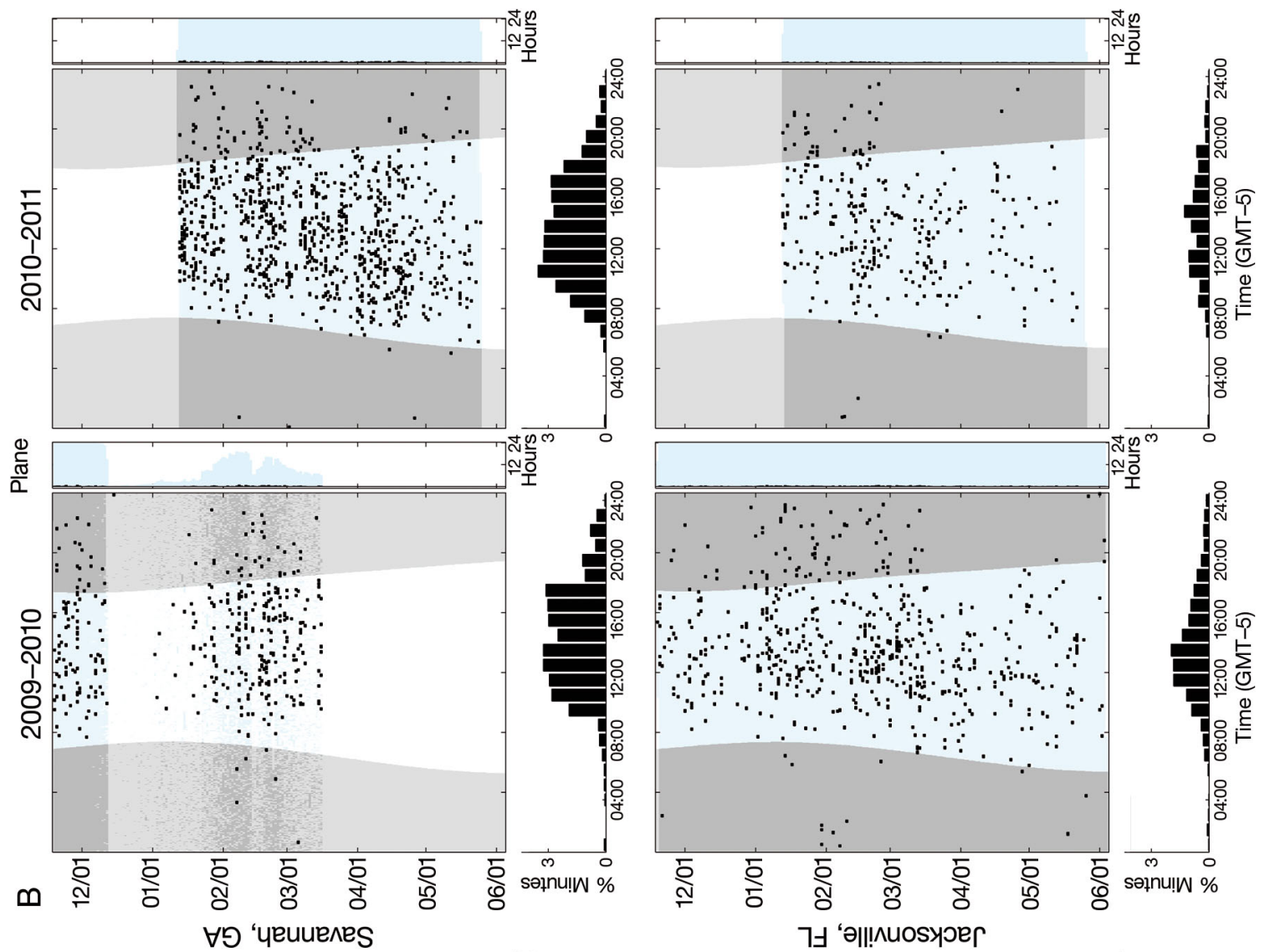

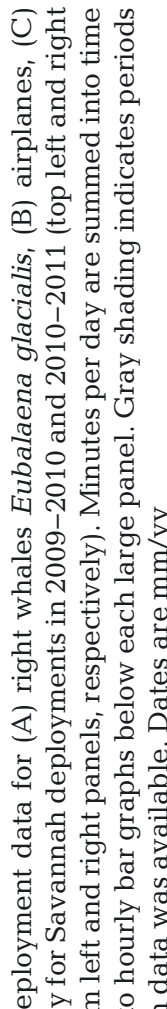

웡 명 염

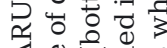

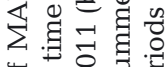
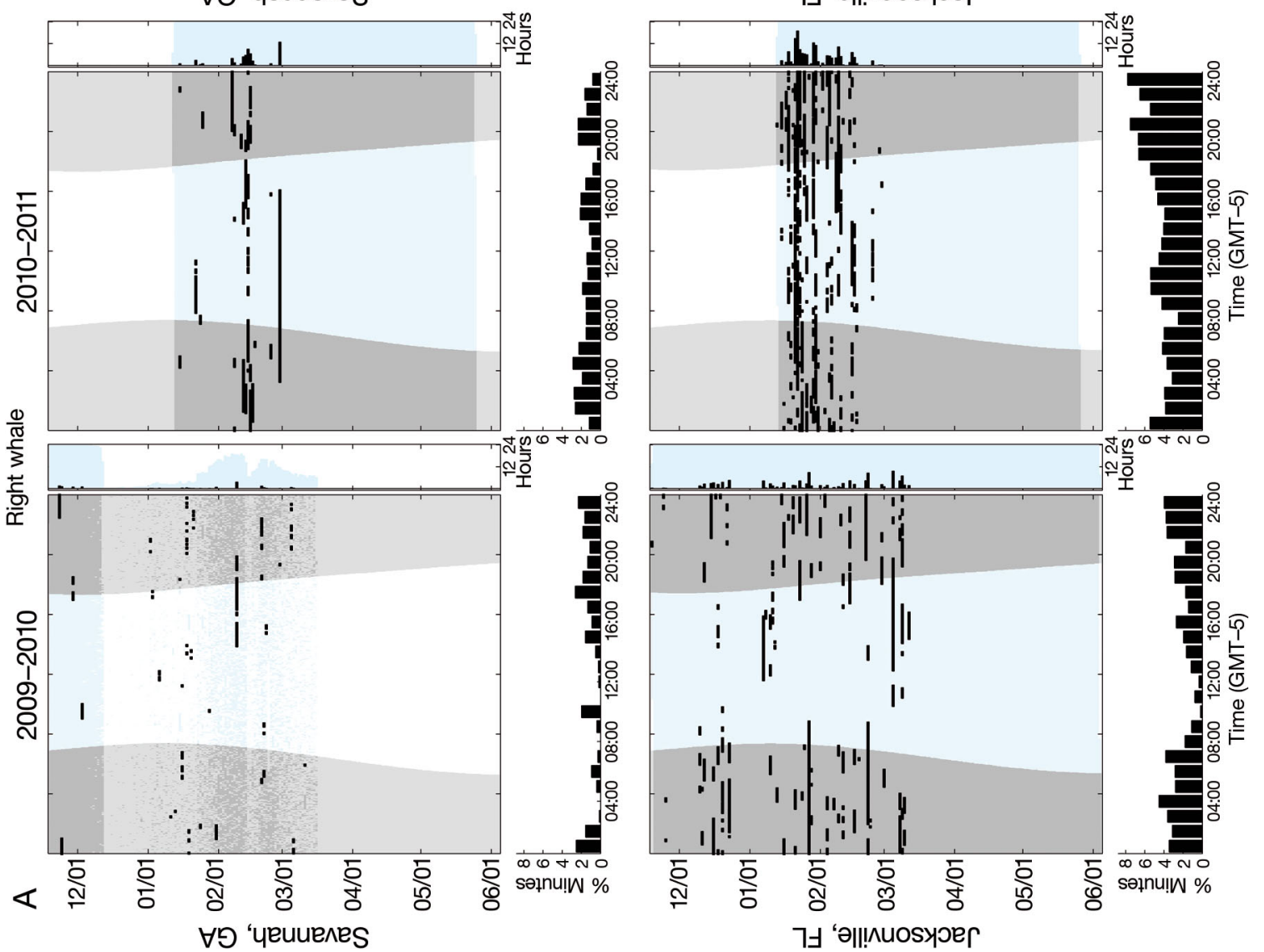

궁

들 의

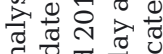

ฮै पै द्व

结 둥응

$\exists$ प्त

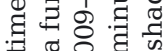

牙

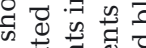

: 잉

$\because$ a

政

政

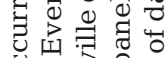

in

द्व

ชิ

प苍苛

㩆

कै

$2, \pi, 0$

互语

द्वै च्व

मे 

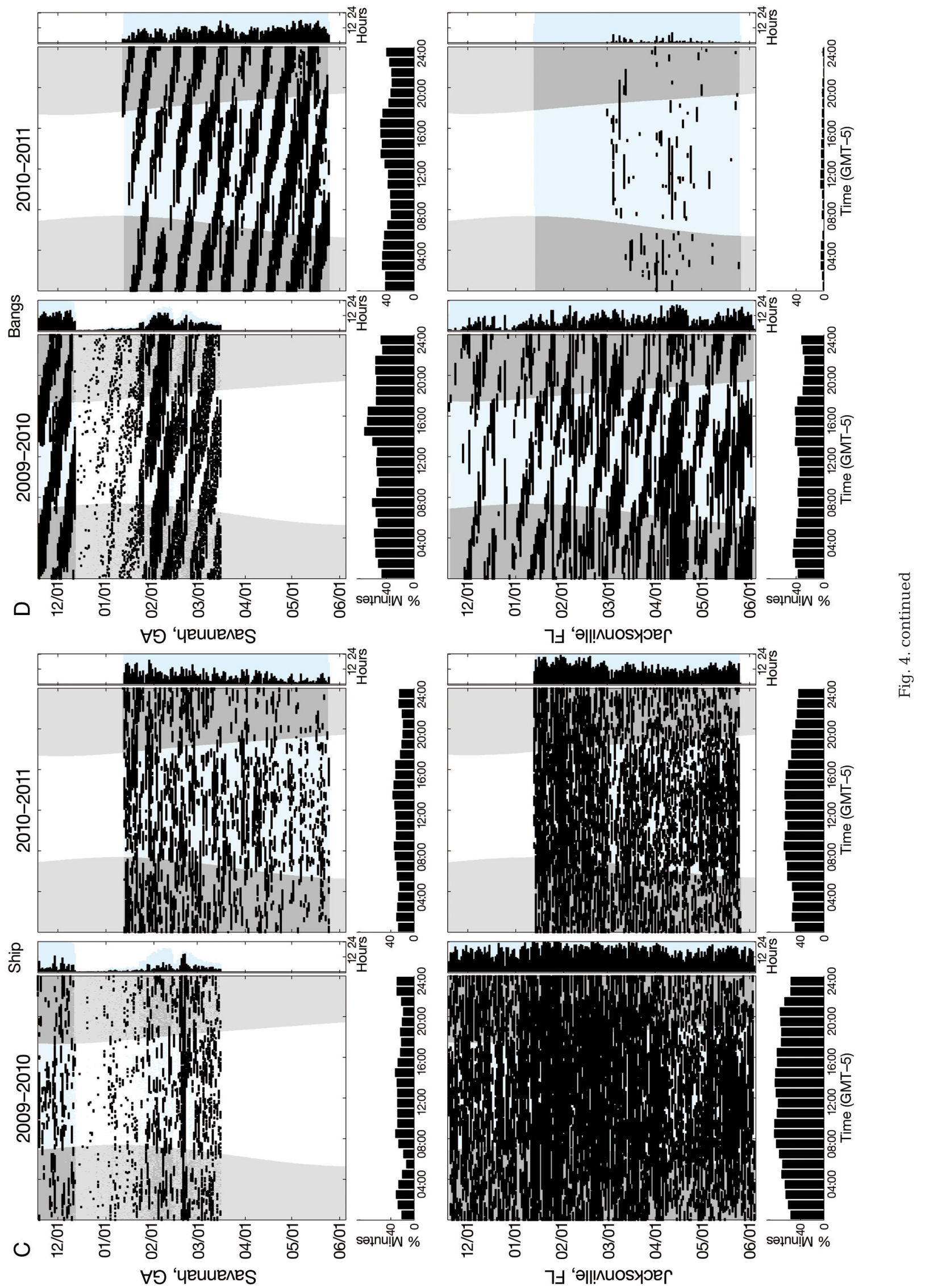
Table 3. Call type presence within right whale calling events, based on data from MARU deployments. The total number of right whale events containing each call type is given, with percentage of total events in parentheses. Only events that could be categorized with certainty to right whales are included in the 'Total' events. The category 'Maybe' indicates additional questionable calling events that might have been humpback whales or other sound sources and typically did not include upcalls

\begin{tabular}{|lcccccccc|}
\hline & Upcalls Impulses & $\begin{array}{c}\text { High } \\
\text { calls }\end{array}$ & $\begin{array}{c}\text { Variable } \\
\text { calls }\end{array}$ & Moans & Total Maybe \\
\hline $\mathbf{2 0 0 9 - 2 0 1 0}$ & & & & & & & \\
Jacksonville & $120(92)$ & $3(2)$ & $8(6)$ & $49(37)$ & $14(11)$ & 131 & 6 \\
Savannah & $63(90)$ & $9(13)$ & $0(0)$ & $13(19)$ & $25(36)$ & 70 & 1 \\
2010-2011 & & & & & & & \\
Jacksonville & $204(94)$ & $14(6)$ & $23(11)$ & $61(28)$ & $2(1)$ & 217 & 7 \\
Savannah & $35(90)$ & $0(0)$ & $6(15)$ & $16(41)$ & $0(0)$ & 39 & 9 \\
\hline
\end{tabular}

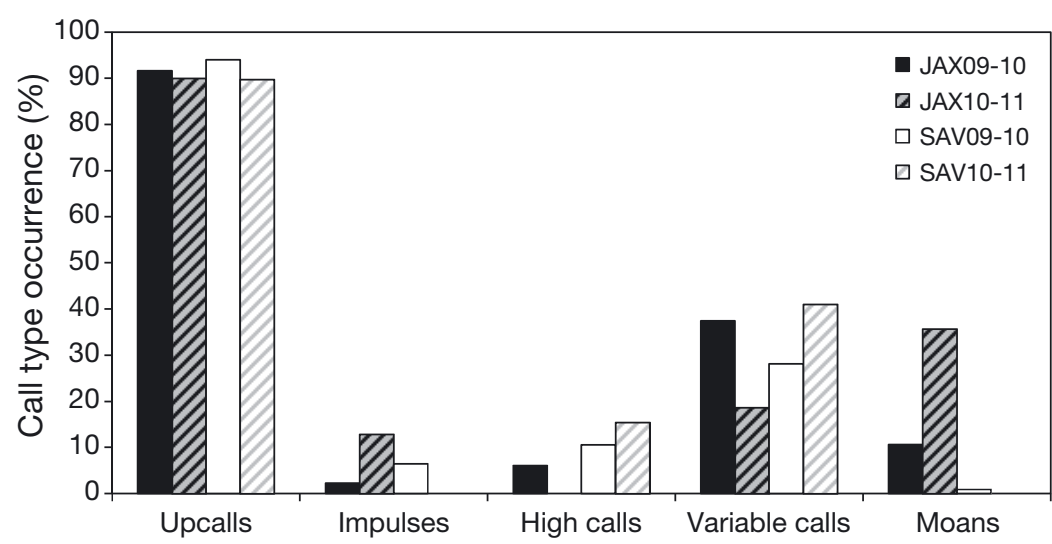

Fig. 5. Percent of right whale calling events containing each of the analyzed call types for the Jacksonville (JAX) and Savannah (SAV) MARU deployments during 2009-2010 and 2010-2011

data), with 7 stereotyped call types exhibiting a strong signature in the long-term LTSA analysis. Of these calls, black drum drumming/mating choruses had the greatest potential to obscure detection of right whale calling bouts. During the most intense periods, these choruses raised ambient noise levels in the LTSA by up to 50 and $40 \mathrm{~dB}$ re $\mu \mathrm{Pa}^{2} \mathrm{~Hz}^{-1}$ at the $80 \mathrm{~Hz}$ fundamental frequency and $160 \mathrm{~Hz}$ harmonic, respectively, over as long as an $8 \mathrm{~h}$ period. At Savannah, black drum chorusing was detected after dusk between March 9 and April 15, 2011, while at Jacksonville, black drum chorusing was detected after dusk between March 13 and April 30, 2010 and February 28 and April 19, 2011. While the other stereotyped call types are not likely to obscure right whale call detections, they exhibited a similar temporal shift between years, occurring approximately 1 to 3 wk earlier during the 2010-2011 season than during the 2009-2010 season. The Savannah 2009-2010 MARU is not included in this portion of the analysis.
Ambient noise levels

Mean hourly ambient noise levels at $150 \mathrm{~Hz}$ ranged between 45.5 and $98.5 \mathrm{~dB}$ re $\mu \mathrm{Pa}^{2} \mathrm{~Hz}^{-1}$, with mean levels of $68.6( \pm 9.3) \mathrm{dB}$ re $\mu \mathrm{Pa}^{2} \mathrm{~Hz}^{-1}$ across all deployments. An inter-instrument comparison of the minimum noise levels recorded per deployment across all frequencies indicates similar minimum noise levels across sites in both years, but a $7.5 \mathrm{~dB}$ re $\mu \mathrm{Pa}^{2} \mathrm{~Hz}^{-1}$ decrease in minimum noise levels in 2010-2011 compared to 2009-2010.

\section{Statistical comparisons}

The variability in noise levels and presence of acoustic events (right whales, ships, planes) was evaluated with respect to site, year, diel period and presence of black drum chorusing. Noise levels were significantly higher off Jacksonville than Savannah, and were particularly high during 2009-2010 season (Fig. 6, Table S1 in the Supplement at www.int-res.com/ articles/suppl/n025p115_supp.pdf). Noise levels were not significantly different between day and night during the period without black drum chorusing. However, once the drum chorusing season began, noise levels increased significantly across all sites and years, with the greatest increases at night (Fig. 6, Table S1). Prior to the drum chorusing season, right whale call presence was higher off Jacksonville than Savannah, was higher during 2010-2011 than 2009-2010, and was higher at night than during the day (Fig. 6, Table S2). No right whale calling event detections were made after the drum chorusing season began (Fig. 6, Table S2). A similar decrease was found in plane detections following the start of the drum chorusing season and the coincident increase in ambient noise levels, although the diel cycle of plane detections is opposite to that of right whale calls (Fig. 6, Table S3). Plane detections were higher off Savannah than Jacksonville, were higher in 2009-2010 off Jacksonville, and were higher in 2010-2011 off Savannah. Following the start of the drum season, ships were also detected less often, and the decrease in detections at night, when black drum chorus, was greater (Fig. 6, Table S4). Duration of 

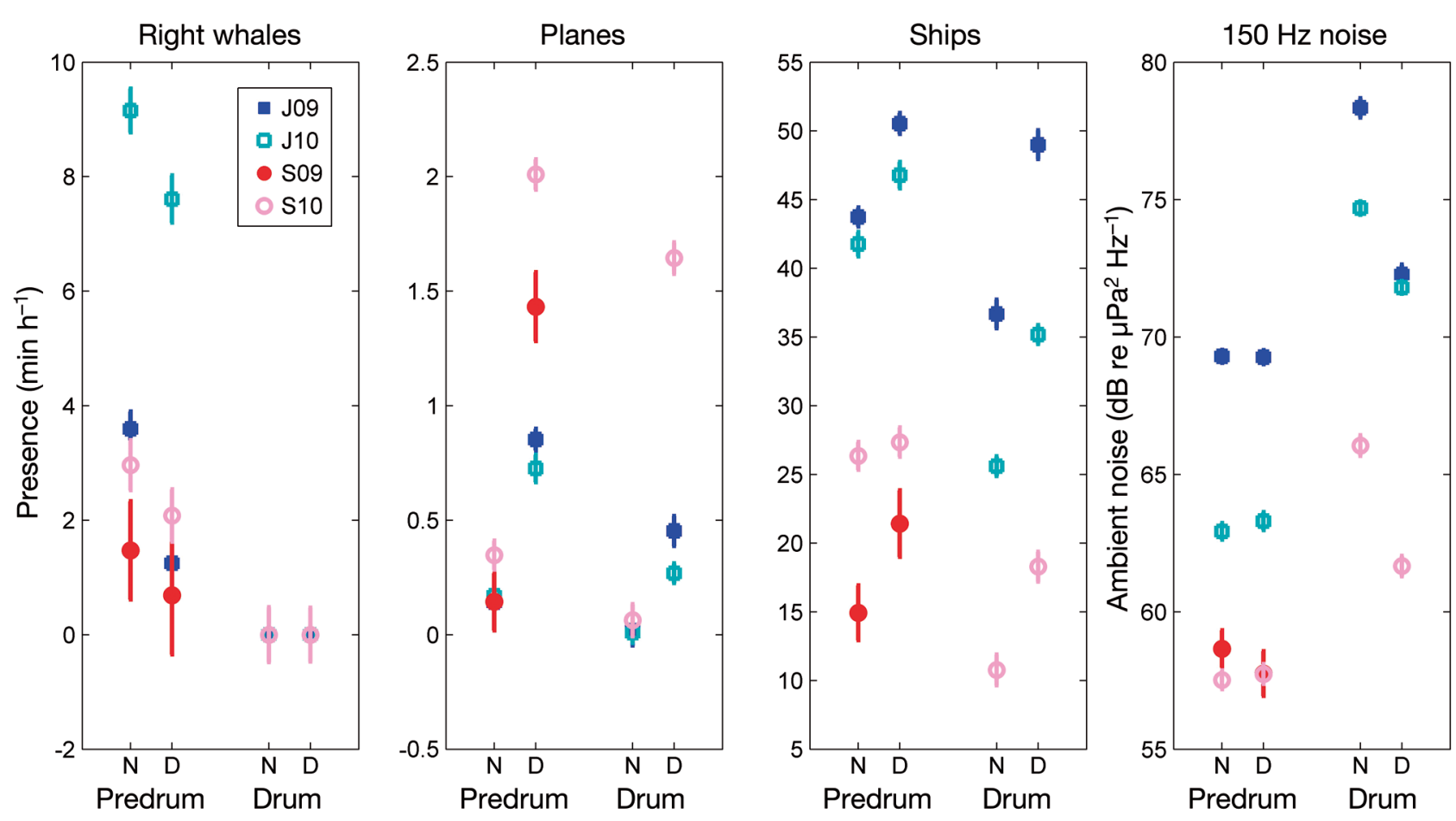

Fig. 6. Results of Tukey-Kramer multi-comparison tests of MARU deployment data for the effects of site (Jacksonville = J, Savannah = S), deployment year $(2009-2010=09,2010-2011=10)$, diel period (night = N, day = D), and drum chorus presence (absence $=$ PreDrum, presence $=$ Drum $)$ on the acoustic occurrence of right whale calls, planes, ships, and $150 \mathrm{~Hz}$ ambient noise levels. Markers represent the mean duration of occurrence $\left(\mathrm{min}^{-1}\right)$ for each acoustic event type and ambient noise levels $\left(\mathrm{dB}\right.$ re $\left.\mu \mathrm{Pa}^{2} \mathrm{~Hz}^{-1}\right)$ for noise at $150 \mathrm{~Hz}$; lines extending from markers encompass $1 \mathrm{SD}$. Significant factors and interactions are described in the text

ship noise presence was higher off Jacksonville than Savannah. Off Jacksonville, duration of ship noise presence was higher in 2009-2010, while off Savannah, it was higher in 2010-2011.

During periods without tidal banging noise or drum chorusing, the presence of right whale, plane, and ship events were each correlated with recorded mean noise levels at both hourly and daily scales (Fig. 7). At both hourly and daily scales, the durations of right whale calls and airplane presence were negatively correlated with mean ambient noise levels. At hourly scales, the duration of presence of ship noise was positively correlated with ambient noise levels. However, at daily scales, the duration of ship noise presence was negatively correlated with mean ambient noise levels at Savannah and positively correlated at Jacksonville (Fig. 7).

\section{Autobouy detections}

During the 2009-2010 deployments, right whale calls were first detected on the Autobuoys on November 24, 2009 at both sites, while during the 2011 deployments, they were first detected on January 13 and 15 off Jacksonville and Savannah, respectively. At Jacksonville, the last right whale detections occurred on April 16, 2010 and February 24, 2011, while at Savannah, the last right whales were detected on March 15, 2010 and February 28, 2011 (Table 4). Of confirmed calls with scores $>8$, a total of 711 calls and 469 calls were detected in 2009-2010 and in 2010-2011, respectively. Daily number of confirmed automated detections ranged between 0 and 35 across deployments, and the mean number of detections per day was $4.3 \pm 7.0$ and $1.7 \pm 4.5$ for the Jacksonville and Savannah 2009-2010 deployments, and $7.4+8.2$ and $2.3+4.1$ for the Jacksonville and Savannah 2011 deployments, respectively (Fig. 8).

\section{Visual surveys}

In 2009-2010, the first and last sightings from the SEUS aerial surveys were on November 28, 2009 in the SCGA region and April 5, 2010 in the SEWS region, respectively. In 2010-2011, the first and last sightings were on November 18, 2010 and March 26, 2011, in the SCGA and NEWS regions, respectively. Comparison of visual sightings between years indi- 

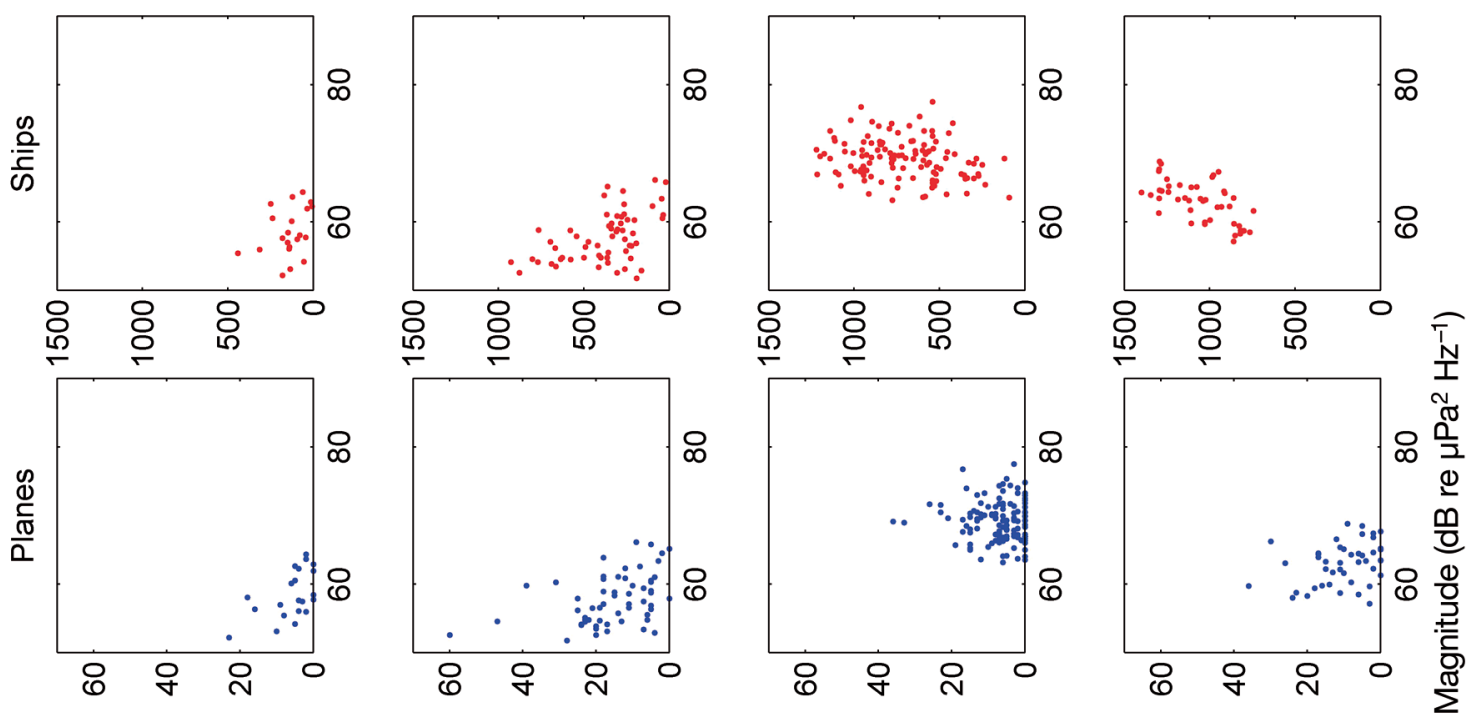

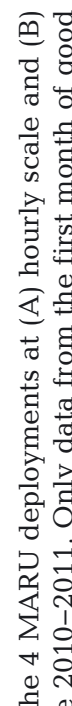
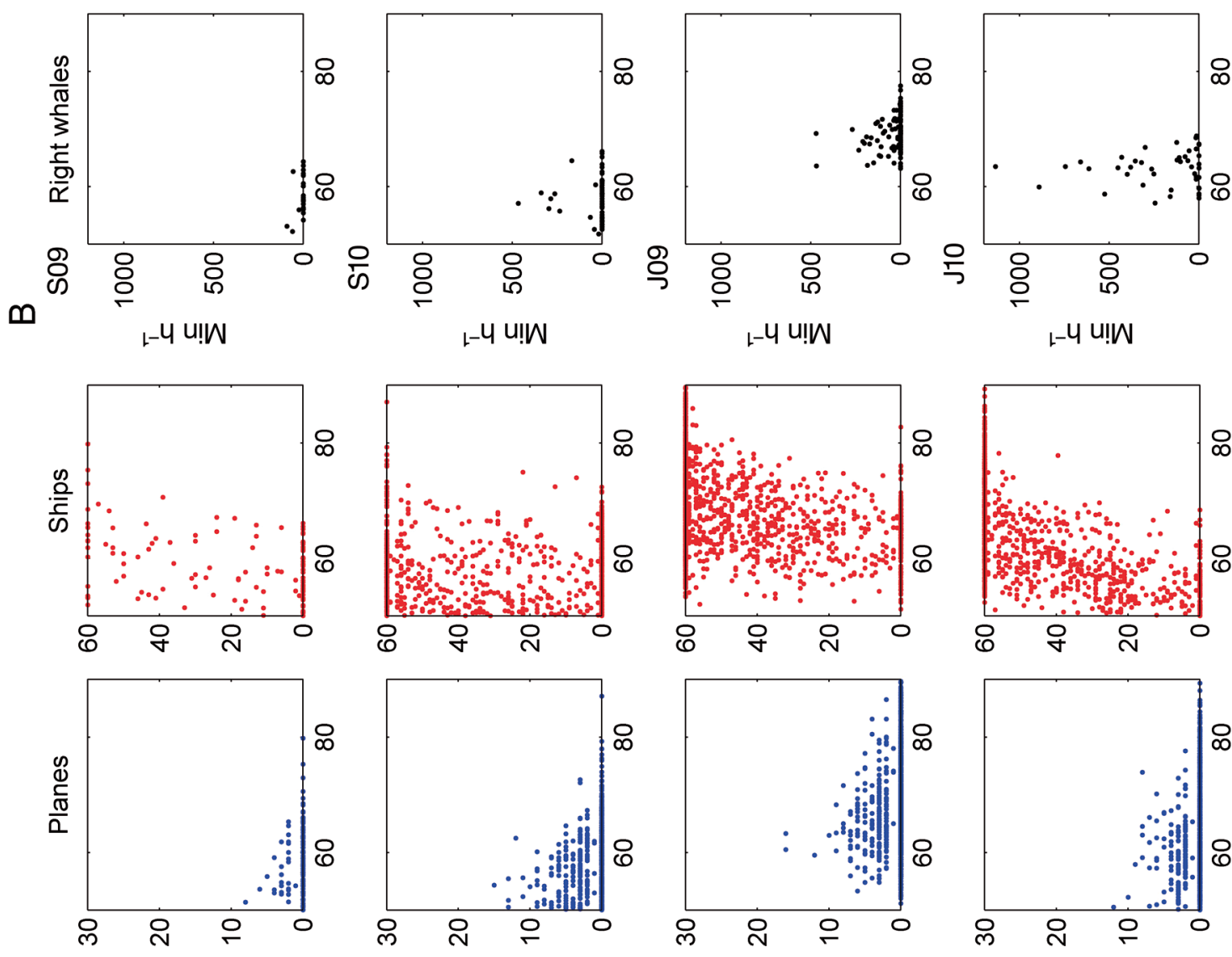

$\infty$
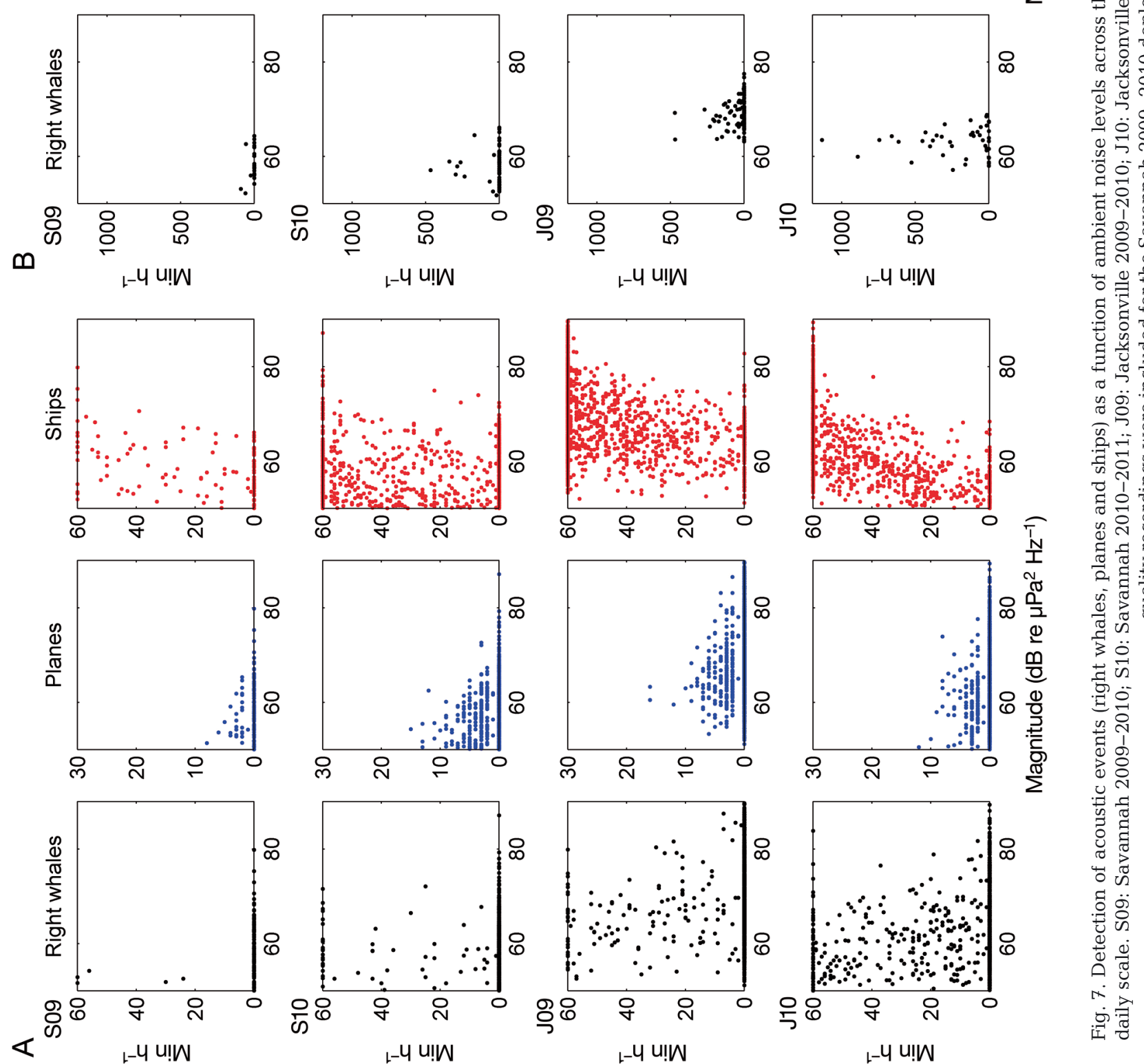


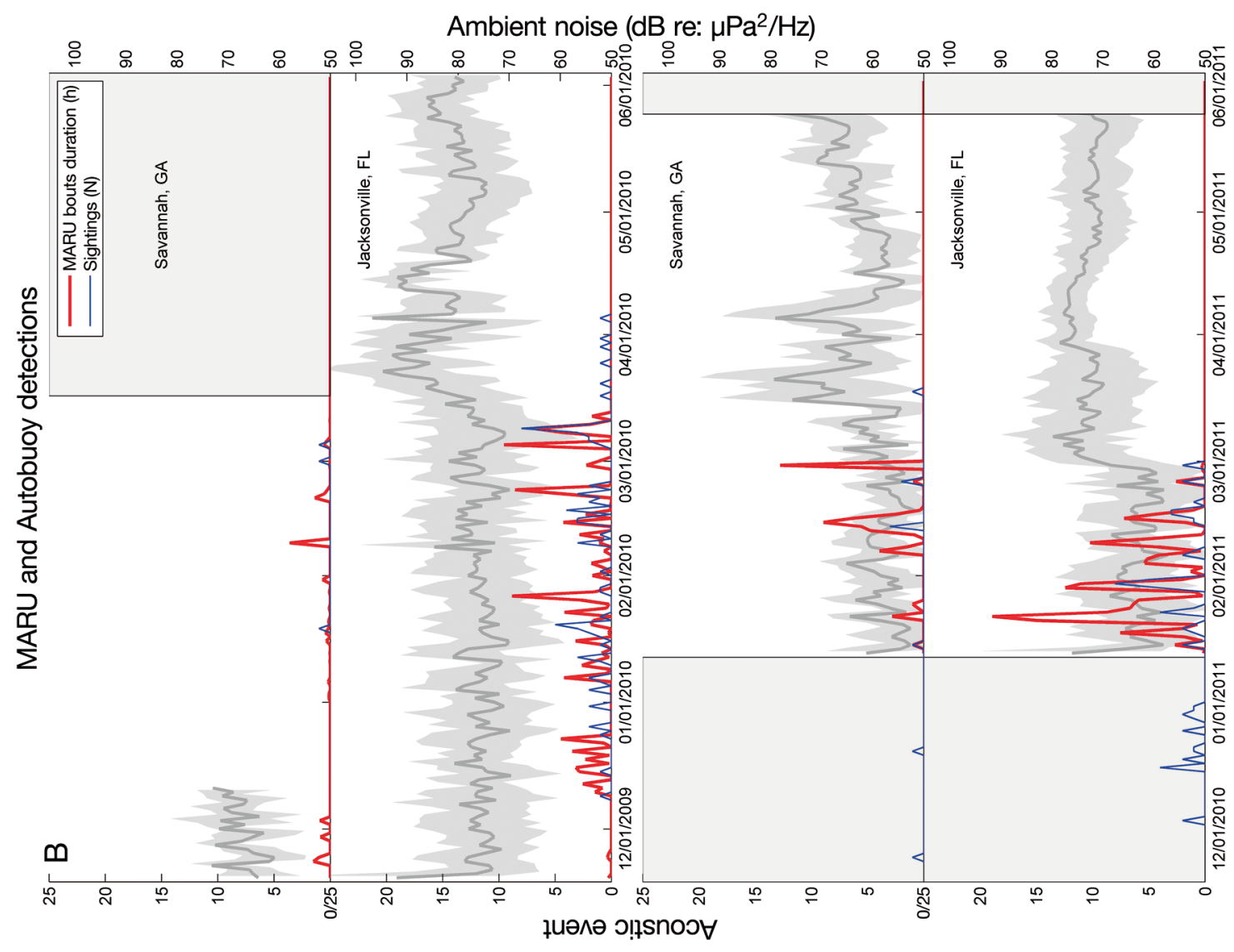

当宇

중

잉 ฮ

这可

ชิ

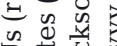

品票

记 ?

के :

ज㻤范

శี

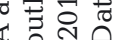

虫

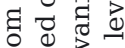

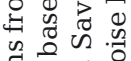

동 웅

ه

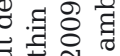

定击

궁

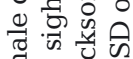

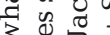

근유

a

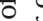

동 용

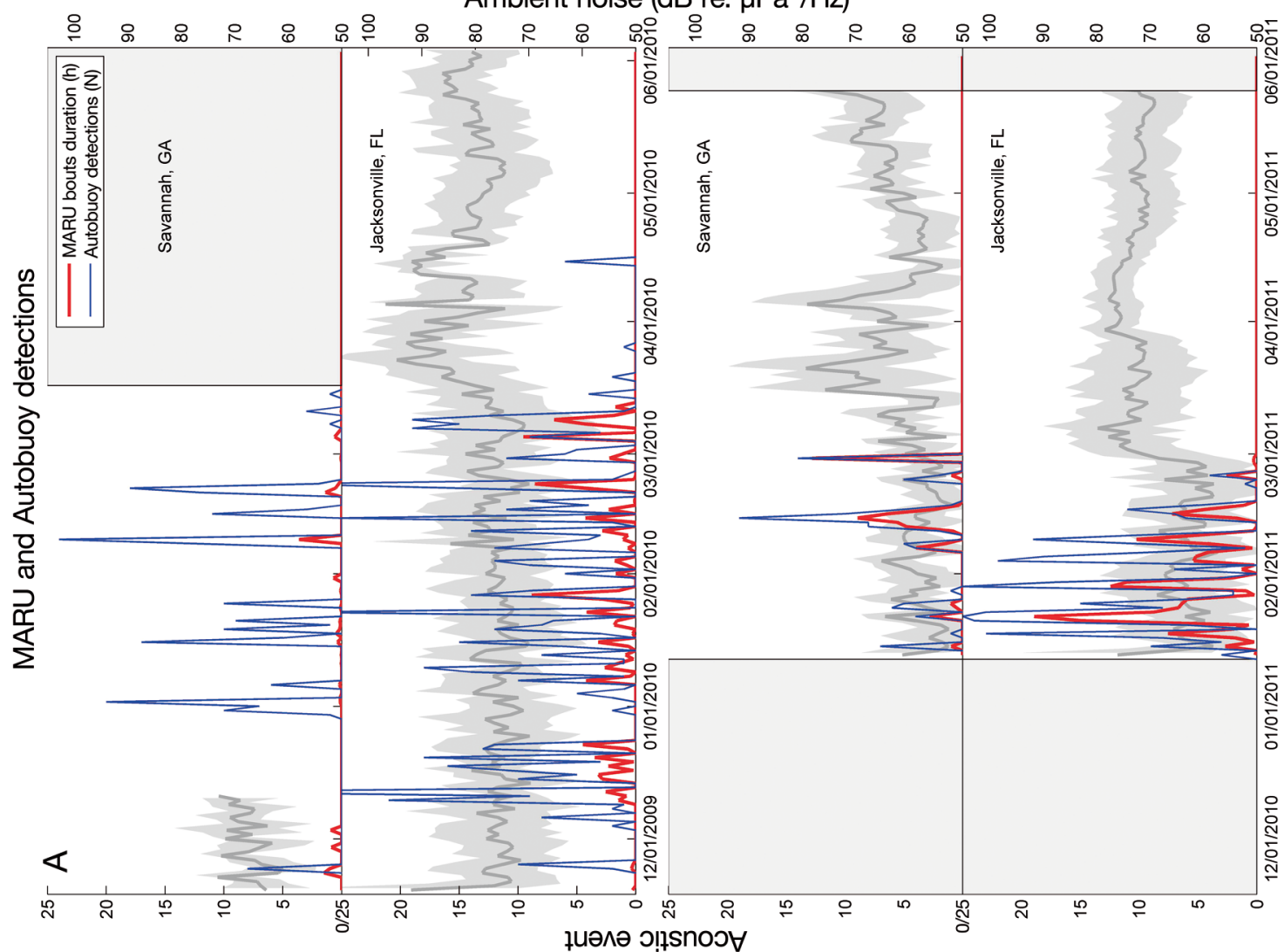

리류 월

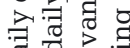

西的西

两完

is वृ व

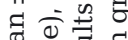

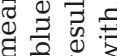

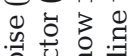

政

若要造

卷雚

तै छ్ हี

㐱节 물

은

눙요

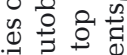

वृ द

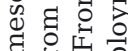

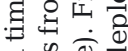

:

氜 ?

:

द्वे

$\infty$. 유

象曹文 

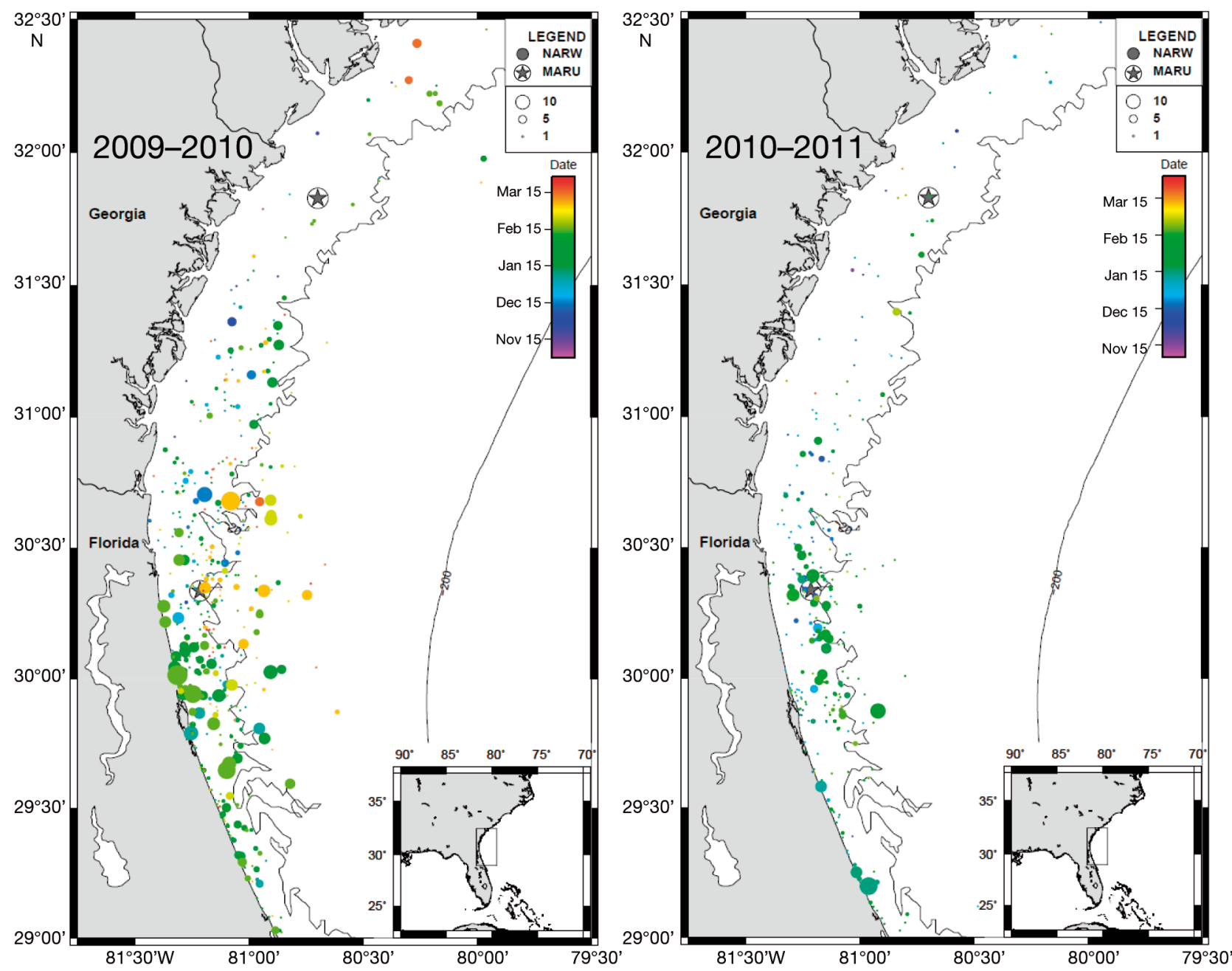

Fig. 9. Map of aerial survey sightings for 2009-2010 and 2010-2011 seasons. (O) NARW: North Atlantic right whale sightings. The size of the circle indicates group size as shown in the inset legend and the color indicates time of year as shown in the vertical bar. (

2010, for a total 2009-2010 season duration of $149 \mathrm{~d}$. Right whales were first detected visually on November 18, 2010 and last detected visually on March 26, 2011, with a modified total 2010-2011 season duration of $73 \mathrm{~d}$ from the start of acoustic effort on January 13, 2011.

A comparison of acoustic detection methods indicates high temporal correlation between the Autobuoy automated upcall detector and manually selected calling events on the associated MARU LTSAs (Fig. 8). Correlations between daily number of Autobuoy upcalls and daily number of minutes with MARU detections were significant, ranging between 0.55 and 0.89 among the 4 deployments, with higher correlations during the 2011 deployments (Table 4). While correlations between Autobuoy and MARU detections per day were high, there were a number of days, across deployments, when only one instrument yielded detections (Table 4). Days per season with Autobuoy detections ranged between 13.4 and $42.5 \%$, days with MARU detections ranged between 17.4 and $45.2 \%$, and the difference between methods ranged between 2 and $13 \mathrm{~d}$ ( 2.7 to $8.7 \%$ of days in season). Neither acoustic method was consistently better than the other, and the methods yielded more similar results in the 2010-2011 than the 2009-2010 season. The deployment with the lowest amount of overlap was Savannah 2009-2010 in which the MARU had a large percentage of corrupt data. On days where no calls were detected on the MARU but detections were made on the Autobuoy, upcall detections on the Autobuoy tended to be sparse, with only 1 to 2 upcalls, (Fig. 8) and these often occurred later in the season, during black drum chorusing. When detec- 
tions are combined over both instruments, right whales were detected on $46 \%$ of days of the season off Jacksonville, and on $25 \%$ of days of the season off Savannah.

By comparison, visual survey effort occurred on 49 to $54.8 \%$ of days of the season off Jacksonville and 8.7 to $12.3 \%$ of days of the season off Savannah. Of days with visual survey effort, right whales were detected within $20 \mathrm{~km}$ of the Jacksonville site on 34.2 to $42.5 \%$ of days, and within $20 \mathrm{~km}$ of the Savannah site on 15.4 to $33.3 \%$ of days. For 3 of the 4 acoustic deployments (Savannah 2009-2010 and both Savannah and Jacksonville 2010-2011), there were acoustic detections on nearly all days with visual detections within $20 \mathrm{~km}$ of the acoustic site. Off Jacksonville in 20092010, there was a greater degree of mismatch, with acoustic detections on only 25 of $40 \mathrm{~d}$ with visual sightings. However, there were a high number of days with acoustic detections (72) on this deployment, and by combining results from visual and acoustic methods, right whales were detected off Jacksonville on $58.4 \%$ of days of the season.

\section{Interannual temperature variability}

Mean daily temperatures and ranges across the 5 NDBC buoys from November 15 to April 15 were

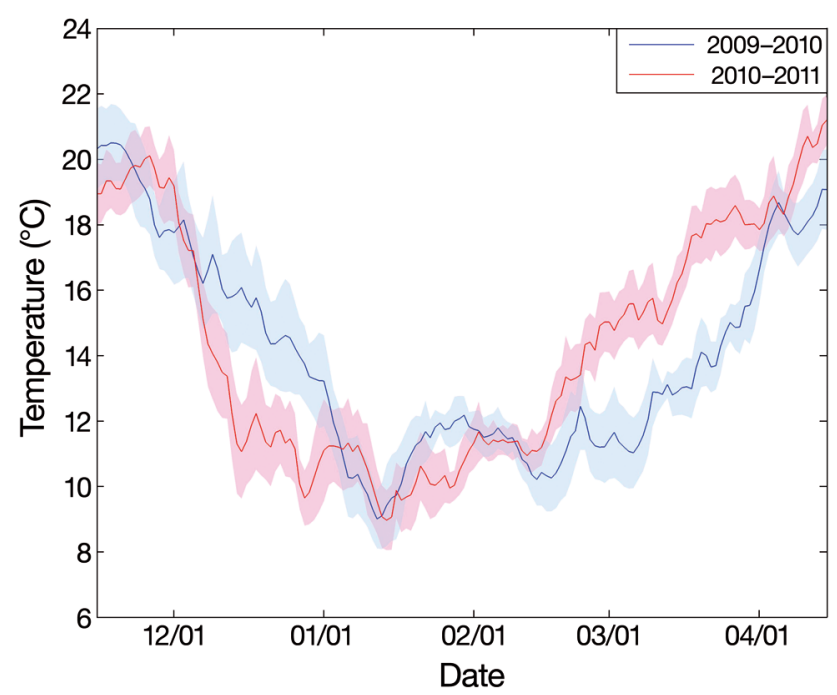

Fig. 10. Comparison of mean \pm 1 SD daily sea surface temperatures (SST) between the 2009-2010 and 2010-2011 right whale calving seasons. Given the large spatial area represented (data are composite hourly means and SDs for the 5 inshore buoys off Jacksonville, FL, and Savannah, GA), there is considerable variability across hours and locations but, on average, temperatures cross the 14 and $16^{\circ} \mathrm{C}$ marks approximately 3 and 2 wk earlier, respectively, in 2010-2011 than in 2009-2010 similar between the deployment seasons of 20092010 and 2010-2011. The mean calving season temperatures were $12.98 \pm 2.8{ }^{\circ} \mathrm{C}$ in $2009-2010$ and 14.4 $\pm 3.8^{\circ} \mathrm{C}$ in $2010-2011$ and daily mean temperatures ranged between 9.0 and $20.5{ }^{\circ} \mathrm{C}$, and between 9.0 and $21.2{ }^{\circ} \mathrm{C}$ in 2009-2010 and 2010-2011, respectively. The most distinct difference between years was in the timing of cooling down and warming up, which occurred approximately $2 \mathrm{wk}$ earlier in the 2010-2011 season compared to the 2009-2010 season. Temperatures cooled below $15^{\circ} \mathrm{C}$ on December 19, 2009 and December 7, 2010, while temperatures warmed above $15^{\circ} \mathrm{C}$ on March 28, 2010 and March 12, 2011 (Fig. 10).

\section{DISCUSSION}

\section{Effectiveness of acoustic monitoring}

North Atlantic right whales exhibit a seasonal presence on the calving grounds, occupying the region between November and April (Kraus et al. 1986, Winn et al. 1986). As anticipated, during this study, right whales were detected within these months from all survey platforms (MARUs, Autobuoys, and visual surveys). From the first to the last detection across methods, right whales were present in the SE calving grounds for $149 \mathrm{~d}$ in 2009-2010 and for $128 \mathrm{~d}$ in 2010-2011, with 73 d of acoustic effort in the 20102011 season. Within these time periods, right whales were acoustically detected on 25 and $26 \%$ of days off Savannah (at the northern edge of the calving grounds) and on 48 and $47 \%$ of days off Jacksonville (in the center of the calving grounds) during the 2009-2010 and 2010-2011 deployments respectively. By comparison, when there was aerial survey effort within $20 \mathrm{~km}$ of each site, right whales were detected a similar proportion of days, with detections on 15 and $33 \%$ of days off Savannah and 34 and $43 \%$ of days off Jacksonville during the 2009-2010 and 2010-2011 seasons respectively. An important consideration is that, due to weather constraints and plane availability, aerial surveys were only able to survey these areas on 49 to $55 \%$ of days off Jacksonville and 9 to $12 \%$ of days off Savannah. Therefore, the use of continuous acoustic monitoring increased the number of days per season with right whale detections by 2- to 10 -fold per deployment (Table 4) providing valuable information on the presence of right whales in the area for use in mitigation.

Providing right whale presence information in near real time, using technology like the Autobuoy, has 
great potential for improving ship-strike mitigation through continuous monitoring of the region. The Autobuoy uses an automated upcall detector to determine and report presence of right whales. A comparison of the percent of days with acoustic detections on either the continuous archival MARU recordings or the Autobuoy shows that the automated upcall detector we used detected whales on 87 to $100 \%$ of total days with acoustic detections, for the 3 deployments that had high quality data available. By comparison, MARU right whale detections from the LTSA analysis were made on 69 to $95 \%$ of days with acoustic detections from these 3 deployments. The LTSA analysis method was used to ensure all call types were detected, and found that 90 to $94 \%$ of right whale calling events on the calving grounds included upcalls. Therefore, it is not surprising that the Autobuoy had such high detection rates. The lower percentage of detections from the MARU LTSA analysis occurred during deployments that contained the tidally-associated banging noise and black drum chorusing. Missed detections on the MARU may be an artifact of temporal averaging in the LTSA process, since bin resolution was $5 \mathrm{~s}$, while right whale calls and broadband bangs are approximately $1 \mathrm{~s}$ and $0.1 \mathrm{~s}$ in duration respectively. A higher temporal resolution spectral analysis such as that used by automated detectors (Gillespie 2004, Urazghildiiev \& Clark 2006) is likely better able to detect calls under these conditions. Developing similar call detectors that incorporate additional call types will likely improve detection of calling right whales for both recording methods. Considering the frequent occurrence of acoustic detections, the high percentage of calling events that include upcalls, and the high correlation between the automated Autobouy upcall detections and the manually detected calling events on the MARUs, these results suggest that the use of Autobuoys for right whale ship-strike mitigation will be effective for detecting calling right whales on the calving grounds.

\section{Seasonal and interannual variability}

A comparison of the occurrence of right whale call detections across sites and years finds more detections at Jacksonville than Savannah, and fewer detections in 2009-2010 than 2010-2011. Similarly, there were more sightings near Jacksonville; however, there were more sightings and more identified individuals in 2009-2010 than 2010-2011. The finding of greater acoustic detections and visual sight- ings at Jacksonville compared to Savannah is expected as Jacksonville falls within the right whale critical habitat for right whale calving, while Savannah is just north of this region (Keller et al. 2012). The change in acoustic detections at Jacksonville between years is interesting in that minutes with call detections were fewer and more constant across the 2009-2010 season, while minutes with call detections were greater in 2010-2011 and peaked in January. This leads to the question of whether the increase in call detections in the 2010-2011 season reflects a change in: (1) masking effects from ambient or system noise; (2) sound propagation conditions; (3) animal density or distribution, possibly related to local environmental conditions or long-term reproductive cycles; (4) calling behavior; or (5) a combination of these factors. Ambient noise levels at Jacksonville were $6 \mathrm{~dB}$ re $\mu \mathrm{Pa}^{2} \mathrm{~Hz}^{-1}$ higher in 2009-2010 than 2010-2011 (Fig. 6) and may have resulted in higher signal to noise ratios and subsequently greater acoustic detection ranges in 2010-2011. Additionally, the presence of the tidally-associated banging sound was minimal at the Jacksonville site in 2010-2011 compared to 2009-2010, resulting in less lost acoustic data in 2010-2011 and hence more chances for detections. When considering whether changes in animal density or distribution, or calling behavior also affected the increase in detections in 2010-2011, we know from visual surveys that there were fewer animals present on the calving grounds in 20102011, but cannot evaluate changes in calling behavior or distribution with single autonomous recorders. However, we can consider environmental changes that may have affected density or distribution and large-scale distribution patterns found during visual surveys. Changes in SST affect right whale distribution on calving grounds, with animals found further south in colder years (Keller et al. 2006, 2012). Both the 2009-2010 and 2010-2011 calving seasons were colder years (compared to prior years), but mean temperatures were lower in 2009-2010 than in 20102011 and a greater number of right whale sightings occurred to the south in 2009-2010. While aerial surveys found contrasting results to acoustic surveys, with a greater number of sightings and individuals in 2009-2010, those whale sightings were more widely dispersed over the shelf in 2009-2010, while they were more clumped with a narrow distribution centered near the $20 \mathrm{~m}$ isobaths (where the MARUs are located) in 2010-2011 (Fig. 9). Based on these comparisons with visual sighting distribution data, environmental data, and other acoustic events, we suggest that both animal distribution and ambient noise 
conditions affected right whale acoustic detections, such that in 2010-2011, the smaller number of animals spent a greater proportion of time within the detection range of the MARU and that the detections ranges may have been larger, as SNRs would be higher with lower ambient noise levels. It is important to note that instruments were not calibrated prior to each deployment, therefore, we cannot rule out differences in instrument sensitivity between years. While instrument-specific differences are likely a component of the decreased ambient noise levels between years, this is expected to be minimal.

The high-temporal resolution of PAM studies can offer insight into temporal changes in migration timing between years. Initial investigations into the first $2 \mathrm{yr}$ of monitoring at Jacksonville, FL, indicate that the last right whale call detections of the season occurred 2 wk earlier in 2011 than 2010 (late February vs. mid-March), coinciding with a 1 to 3 wk earlier onset of calling for all fish call types and an approximately 2 to 3 wk earlier warming of surface waters (Fig. 10). The onset of drum calling coincided with the end of right whale call bout detections during all MARU deployments. This could be an artifact of masking, given that (1) the frequency range of black drum calls overlaps that of right whale upcalls, (2) ambient noise conditions at $150 \mathrm{~Hz}$ increased by about $40 \mathrm{~dB}$ re $\mu \mathrm{Pa}^{2} \mathrm{~Hz}^{-1}$ during black drum chorusing, (3) black drum chorusing and right whale detections occur more often at night, and (4) coincident decreases in detections of ships and planes occurred at the start of peak black drum chorusing. However, aerial survey visual sightings and acoustic detections decrease at the same time each year, indicating whales are in fact moving out of the area at this time. The similar interannual shift in timing of the end of right whale call detections, visual sightings, and onset of all fish call types by 2 to 3 wk earlier in spring 2011 than 2010 suggests that the right whales and fish were each responding to similar changing environmental conditions as whales departed the area and fish spawning began. Right whales prefer cooler waters, with peak densities on the calving grounds occurring at $14^{\circ} \mathrm{C}$ (Keller et al. 2006, 2012, Garrison 2007) while drum spawning typically occurs when temperatures are between 14 and $20^{\circ} \mathrm{C}$ (Collins et al. 2001). Across the NDBC buoy sites in the right whale calving grounds, mean SSTs passed the 14 and $16^{\circ} \mathrm{C}$ levels between 2 and 3 wk earlier in 2011 than 2010, correlating well with the shift in whale and fish behavior. In addition to temperature, peaks in drum spawning are also related to moon phases (Collins et al. 2001) and it is possible that right whales also respond to additional cues, including varying illumination or tidal effects, the acoustic cue of increased fish calling, or other oceanographic conditions, as a signal to begin their migration north. Further investigation into the timing of interannual call occurrence and these potential cues may improve our understanding of what environmental changes signal the end of the calving season for right whales and may help predict their movements and our ability to predict distribution during migration, thereby leading to reduced ship strikes.

The use of multiple instruments along migration routes of North Atlantic right whales can indicate the timing of pulses of migrating animals transiting between regions (e.g. Burtenshaw et al. 2004, Širović et al. 2004, Stafford et al. 2007, Mellinger et al. 2011, Morano et al. 2012). The increase in call detections in late February 2011 at Savannah may indicate a pulse of animals making their migration north at the end of the calving season. This coincides with the end of call detections off Jacksonville and a decrease in sightings from aerial surveys. No such pulse was evident in the beginning of the season which may indicate that animals are less vocally active or more temporally dispersed on their southern migration or that a southward pulse occurred before the beginning of the acoustic deployment. Given there were no recordings in fall 2010 (MARUs were deployed in mid-January 2011), it is likely that if a southward pulse occurred, it was missed. However, no such pulse was evident in the 1 mo of good quality recordings from mid-November to midDecember 2009. Similarly, if an end of season pulse occurred in spring 2010 at Savannah, it was missed due to instrumentation failures. In recent years, more right whales have been travelling south to the calving grounds in winter, including adult males, juveniles, and non-calving females (e.g. Jackson et al. 2011a). This increase in numbers of animals may make a 'migration' pulse easier to detect than in prior years, but also more difficult to interpret since the cause of migratory behavior in these non-calving animals remains unknown, as does their associated acoustic behavior. This acoustic pulse could just represent a small group of highly vocal animals spending a brief period of time near the Savannah MARU. If whales do migrate north in a pulse, this can provide important information for management along the migration corridor. If whales are 'clumped' and the timing can be predicted annually from oceanographic changes, mariners can be put on higher alert at this time to decrease risk of ship strike. However, given the missing data in 2009- 
2010, this may have been a one-time phenomenon and it is possible that it just represents a small, highly vocal group of whales heading north rather than a large group of whales. Efforts are underway to analyze more seasons of data, localize calling whales, and develop a better understanding of calling behavior to help answer this question.

\section{Diel variability}

A diel pattern of increased minutes per hour with right whale call detections at night compared to day time at Jacksonville may indicate a diel change in calling behavior. Similar nocturnal increases in call detections have been described in numerous studies from both vessel-based and bottom-mounted sensors across right whale species and habitats (North Atlantic right whales, foraging habitat [Matthews et al. 2001, Morano et al. 2012]; North Atlantic right whales, calving grounds [Marine Acoustics Inc. 1997]; North Pacific right whales, foraging habitat [Munger et al. 2008]; Southern right whales, calving grounds [Clark 1983]). A few studies have found different diel patterns, including a diurnal increase (Mellinger et al. 2007a) and a twilight peak (Mussoline et al. 2012) at sites on the North Atlantic foraging grounds. Hypotheses for the driving factors behind the increased calling at a given time of day frequently consider foraging activity, and Parks et al. (2011) found that whales called less during foraging and more during traveling and social activity. However, as right whales rarely, if ever, forage on the calving grounds (Kraus et al. 1986), hypotheses about foraging behavior are not appropriate in this habitat, and other reasons must be considered. Baleen whale vocalizations are typically produced in a social context, for example to maintain contact with conspecifics, in agonistic displays, or to attract mates (Baumgartner \& Fratantoni 2008). Right whales' increased nocturnal acoustic activity on the calving grounds could reflect an increased need to remain in contact when vision is limited at night. In this study, we find that shipping noise durations were particularly high at Jacksonville and a comparison of diel patterns of ship noise occurrence with right whale call detection occurrence shows an inverse pattern. This raises the question of whether right whale calling activity truly varies on a diel scale or whether it remains constant throughout the day and the diel pattern described is an effect of masking by ship noise. Similarly, SST varies on a diel cycle, and resulting changes in sound propagation could cause the variability in call detec- tions that we see here. Regardless of the cause of diel variability in right whale call detections, the greater ability to detect whales at night when they cannot be seen highlights the value of PAM as a monitoring and mitigation tool as real-time monitoring can alert ships to whale presence when visual methods cannot.

\section{Ambient noise and acoustic events}

A variety of noise sources occur in shallow water environments which have the ability to obscure detections of right whale calls and can affect interpretation of the presence of calling right whales during PAM work. Ambient noise levels between 100 and $1000 \mathrm{~Hz}$ are dominated by shipping noise, wind dependent bubble and spray noise, precipitation, and biologics (Wenz 1962). Wind-dependent noise can increase ambient noise levels by up to $40 \mathrm{~dB}$ re $\mu \mathrm{Pa}^{2} \mathrm{~Hz}^{-1}$ and shipping noise (in shallow waters) can increase baseline levels by 40 to $50 \mathrm{~dB}$ re $\mu \mathrm{Pa}^{2} \mathrm{~Hz}^{-1}$ (Wenz 1962). As expected, detections of right whale calls and planes were negatively correlated with ambient noise levels, at both hourly and daily scales. Also as expected, mean hourly ambient noise levels increased with hourly duration of ship presence. However, at a daily scale, ships were only positively correlated with ambient noise levels at Jacksonville, while they were negatively correlated with noise levels at Savannah. The Jacksonville MARU is located in between the 2 designated shipping lanes for the Port of Jacksonville, so most ships pass close by. The Savannah MARU is close to the Port of Savannah, so ships pass nearby, but it is not near a designated shipping lane. We interpret the differing relationship between ship presence and ambient noise levels at different temporal scales as follows: Ships which pass close to the MARU result in increased ambient noise levels but, overall, the detection of more distant ships is negatively impacted by increases in overall ambient noise levels, similar to findings for whales and planes. The presence of shipping noise in 30 to $74 \%$ of minutes per MARU deployment and the corresponding increase in ship noise likely impacts our ability to detect right whales acoustically, particularly at the Jacksonville site. Fortunately, the noise level rises are temporary and occur at peak levels for approximately 15 min per ship passing. Right whale calling events typically are of longer duration and are detected during the periods between ship passes.

Additionally, it is important to consider the increased noise levels that occur during periods of black drum chorusing and the impact on right whale detectability. 
The highest daily ambient noise levels occurred during the peak black drum spawning season, with levels rising above $65 \mathrm{~dB}$ re $\mu \mathrm{Pa}^{2} \mathrm{~Hz}^{-1}$ at Savannah and above $70 \mathrm{~dB}$ re $\mu \mathrm{Pa}^{2} \mathrm{~Hz}^{-1}$ at Jacksonville. These increased levels resulted in decreased detections of planes and ships, and no right whale calling events were detected once black drum chorusing began. The beginning of black drum chorusing coincided with the end of the right whale season on the calving grounds, and only a handful of visual sightings occurred after this time, so black drum chorusing probably did not have too detrimental an effect on the use of PAM during this study. However, if the timing of black drum spawning begins prior to right whales leaving the area in later years, this effect will need to be re-evaluated.

The remaining sources of ambient noise in this frequency band are wind and waves. When periods with tidal noise, shipping noise, and black drum chorusing are removed, a strong correlation exists between ambient noise levels and both wind speed and wave height at nearby environmental monitoring buoys, suggesting wind and waves explain most of the remaining ambient noise level variability. Periods with higher wind speeds will have lower right whale detectability, and diel variation in winds could influence diel call detectability. At NDBC buoys near Savannah and Jacksonville MARUs, hourly wind speed measurements exhibit a diel periodicity with increased wind speeds at night. Therefore, one would expect decreased right whale call detectability and fewer detections at night, when in fact the opposite was found. During extended periods of high wind, right whales may be less detectable by both visual and acoustic methods.

\section{Unknowns}

\section{Calling behavior}

While we have considered the implications of ambient noise levels on right whale detectability from PAM, we have not been able to investigate the effects of variability in calling on our interpretation of our results. Focal follow studies of North Atlantic right whales on the feeding grounds indicate variability in call type production by individuals during Surface Active Group (SAG) behavior: (1) variable tonal calls are the second most-commonly produced call type after upcalls; (2) gunshots are common and are the only call with a male sex-bias in production; and (3) variable tonal call subcategories such as screams and warbles are mainly produced by adult females and female calves, respectively, during the surface active behavioral state (Parks \& Tyack 2005). Such behavioral, sex- and age-specific variability has important implications for the ability to acoustically detect different members of the population at different times (Parks et al. 2011), and individual call usage patterns are completely unknown for whales on the southeast calving grounds. Right whales on the southeast calving grounds are in a different life stage than those on the northeast feeding grounds, and it is hard to justify the assumption that calling behavior should be the same across habitats. Little is known about mother and calf calling behavior on the calving grounds, and the function and behavioral states of the recent influx of migrating juveniles, adult males and non-calving adult females also remain unknown. To fully interpret changes in density and distribution from PAM, more needs to be known about call type usage, calling rates and source levels and how they vary. This type of information is best obtained from congruent visual and acoustic focal follow studies (e.g. Parks \& Tyack 2005) and use of acoustic tagging technologies (e.g. Johnson \& Tyack 2003, Parks et al. 2011). Focal follow studies on the calving grounds can also help determine which groups are effectively monitored with PAM and whether interannual differences in call detections reflect interannual differences in population makeup, behavioral states or numbers of animals present. Nocturnal focal follows or acoustic tagging could also be conducted to examine whether diel trends in call detections are a result of changes in call behavior. An understanding of site-specific calling behavior is key to understanding the effectiveness of PAM for mitigation. In particular, knowledge of mother-calf calling behavior during the first few months following birth is needed to determine the efficacy of a real-time acoustic monitoring system to detect and protect this critical sub-group.

\section{Sound propagation}

Oceanographic conditions in shallow water environments are highly dynamic and have potential to affect sound propagation over a variety of temporal scales which can affect detection ranges of right whale calls. In this region, SST can vary as much as $4^{\circ} \mathrm{C}$ over the course of a day. Surface warming and cooling can lead to formation of a surface duct with a sound speed gradient of 5 to $10 \mathrm{~m} \mathrm{~s}^{-1}$ being formed within the top meters on a diel cycle (Urick 1975), 
which may affect propagation of whale calls when produced at certain depths. Acoustic tagging studies of calling whales find some species produce calls only at certain depths, with some deep diving odontocetes only producing echolocation clicks below certain depths (e.g. Watwood et al. 2006, Aguilar Soto et al. 2008, Aguilar de Soto et al. 2012) and some baleen whale species producing the majority of tonal calls in shallow waters, even during deep diving foraging behaviors (Oleson et al. 2007, Parks et al. 2011). Since right whales inhabit shallower waters and do not forage during their time on the calving grounds, it is unknown if calling behavior is limited to specific depths. If animals are calling at the surface, calls may become trapped in a surface duct and may result in a shadow zone at the depth of the receiver. If animals are calling below this layer, water depth will effectively be smaller and hence detection ranges may be greater than if the duct were not present. Such an effect can also impact modal propagation, which is important for low frequency sounds in shallow environments. Similarly, semi-diurnal variability in water depth due to tides may be as great as $3 \mathrm{~m}$. Sound attenuation due to cylindrical spreading will increase with increasing water volumes (Richardson et al. 1995) which, at the $17 \mathrm{~m}$ water depths of the acoustic instruments, can lead to an up to $20 \%$ reduction in call detection area around the MARUs at high tide compared to low tide. Wind speed and direction and wave height exhibit diel cycles, and wind and waves are a main source of ambient noise in shallow waters (Urick \& Gaunaurd 1972). In these shallow waters, an increase of $10 \mathrm{~dB}$ noise can lead to a 10-fold decrease in call detection ranges, so diel variability in noise levels could impact the number of whale calls detected during day and night. Additionally, changes in wind and waves can have complex effects on sound propagation as is seen in the formation of interference patterns due to Lloyd's Mirror effect during calm surface conditions (Urick 1975). The magnitude of these possible effects on right whale call detections is unknown. Frequent vertical water sampling in conjunction with detection range calculations from instrument arrays can be used to model these effects and better understand the efficacy of PAM in these shallow water environments.

\section{Detection ranges}

Periodic variability in ambient noise sources and environmental conditions that affect sound propagation indicate that these could have important implications for detection ranges of calling right whales. A key piece of information needed to explain interannual variation, intra-season peaks, ambient noise and sound propagation effects on detection ranges is the location of calling animals. In the cooler, deeper waters found on foraging grounds, spatial localization of calls yielded detection ranges up to 10 and $30 \mathrm{~km}$ for upcalls and gunshots, respectively, for North Atlantic right whales in the Bay of Fundy (Laurinolli et al. 2003) and up to $100 \mathrm{~km}$ for North Pacific right whale upcalls in the Bering Sea (Munger et al. 2011). Detection ranges likely are smaller in the warmer, shallow waters off Florida and Georgia. The ability to localize calling individuals on the calving grounds could help answer questions about changes in animal distribution, density, detection distances, source levels and possibly calling behavior among sites and years. In special circumstances, detection distances can be determined from single instruments, using methods that take advantage of multipath arrivals (Širović et al. 2007) or modal propagation (Wiggins et al. 2004, Munger et al. 2011). These effects were not obvious in our data and localizing whale calls will require instrument arrays. Additionally, greater spatial coverage across the calving grounds could help discriminate shifts in spatial distribution.

\section{CONCLUSION}

PAM offers promise of improved temporal resolution and detectability of right whale presence on the southeast calving grounds, particularly at night and in rough weather conditions. This first look at these temporal trends in call detections highlights its value for both monitoring and real-time mitigation in this setting, while also finding a variety of factors that need to be accounted for to improve its effectiveness. In particular, the shallow water environment has the potential to affect detection ranges of right whales across temporal scales due both to changes in ambient noise levels and to potential effects on sound propagation. To quantify these effects, whale calls need to be geospatially localized relative to the recording array (e.g. Clark \& Clapham 2004) and future work should model temporal variability in ambient noise with respect to call detection ranges. Additionally, sound speed profiles should be calculated throughout the day and over semi-diurnal and spring/neap tidal cycles throughout the detection range to better understand the effects of temporal variability in environmental conditions. Finally, more 
needs to be understood about right whale calling behavior on the calving grounds; this can be addressed by focal follow studies or non-invasive acoustic tagging of mother-calf pairs, surface active groups, and juveniles, including work that continues through the night.

Acknowledgements. We thank the many people who made this research possible from data collection through data analyses. These include the Cornell Autobuoy team: Eric Spaulding, Matt Robbins, Sam Fladung; and the Cornell Autobuoy clip review team: Ashakur Rahaman, Jamey Tielens, Christiana Diamond, Kristin Hodge, Maureen Loman, Bobbi Estabrook, Beth Howard, Annamaria Izzi, Clara MacCarald, Janelle Morano, Charlies Muirhead, Anita Murray, Danielle Nelson, Kaitlin Palmer, Chris Pelkie, Mike Pitzrick, Bethany Roberts, Elizabeth Rowland, and Dan Salisbury. Danielle Cholewiak, Susan Parks, Kaitlin Palmer, Denise Risch, Sofie Van Parijs advised on call classifications and Ana Širović provided advice on ambient noise analyses. We also thank all SEUS visual survey team leaders and observers from the Aquatic Conservation Program, the Ecohealth Alliance, the Fish and Wildlife Research Institute, the Florida Fish and Wildlife Conservation Commission, the Georgia Department of Natural Resources, the New England Aquarium, and Wildlife Trust. Finally, we thank 2 anonymous reviewers whose suggestions greatly improved this manuscript.

\section{LITERATURE CITED}

Aguilar de Soto N, Madsen PT, Tyack P, Arranz P and others (2012) No shallow talk: Cryptic strategy in the vocal communication of Blainville's beaked whales. Mar Mamm Sci 28:E75-E92

Aguilar Soto N, Johnson MP, Madsen PT, Díaz F, Domínguez I, Brito A, Tyack P (2008) Cheetahs of the deep sea: deep foraging sprints in short-finned pilot whales off Tenerife (Canary Islands). J Anim Ecol 77:936-947

> Baumgartner MF, Fratantoni DM (2008) Diel periodicity in both sei whale vocalization rates and the vertical migration of their copepod prey observed from ocean gliders. Limnol Oceanogr 53:2197-2209

Burtenshaw JC, Oleson EM, Hildebrand JA, McDonald MA, Andrew RK, Howe BM, Mercer JA (2004) Acoustic and satellite remote sensing of blue whale seasonality and habitat in the Northeast Pacific. Deep-Sea Res II 51: 967-986

Calupca TA, Fristrup KM, Clark CW (2000) A compact digital recording system for autonomous bioacoustic monitoring. J Acoust Soc Am 108:2582

Clark CW (1982) The acoustic repertoire of the southern right whale, a quantitative analysis. Anim Behav 30: 1060-1071

Clark CW (1983) Acoustic communication and behavior of the southern right whale, Eubalaena australis. In: Payne $\mathrm{R}$ (ed) Communication and behavior of whales. Westview Press, Boulder, CO, p 163-198

Clark CW, Clapham PJ (2004) Acoustic monitoring on a humpback whale (Megaptera novaeangliae) feeding ground shows continual singing into late spring. Proc Biol Sci 271:1051-1057
Clark CW, Borsani JF, Notarbartolo-di-Sciara G (2002) Vocal activity of fin whales, Balaenoptera physalus, in the Ligurian Sea. Mar Mamm Sci 18:286-295

Clark CW, Calupca T, Gillespie D, Von der Heydt K, Kemp J (2005) A near-real-time acoustic detection and reporting system for endangered species in critical habitats. J Acoust Soc Am 117:2525

- Clark CW, Ellison WT, Southall BL, Hatch LT, Van Parijs SM, Frankel AS, Ponirakis D (2009) Acoustic masking in marine ecosystems: intuitions, analysis, and implication. Mar Ecol Prog Ser 395:201-222

> Clark CW, Brown MW, Corkeron P (2010) Visual and acoustic surveys for North Atlantic right whales, Eubalaena glacialis, in Cape Cod Bay, Massachusetts, 2001-2005: management implications. Mar Mamm Sci 26:837-854

Collins MR, Callahan BM, Post WC (2001) Spawning aggregations of recreationally important sciaenid species in the Savannah Harbor: spotted seatrout Cynoscion nebulosus, red drum Sciaenops ocellatus, weakfish Cynoscion regalis, and black drum Pogonias cromis. Final report to Georgia Ports Authority. South Carolina Department of Natural Resources, Charlston, SC

Dugan PJ, Rice AN, Urazghildiiev IR, Clark CW (2010a) North Atlantic right whale acoustic signal processing. Part I. Comparison of machine learning recognition algorithms. IEEE Long Island Systems, Applications and Technology Conf (LISAT 2010):1-6

Dugan PJ, Rice AN, Urazghildiiev IR, Clark CW (2010b) North Atlantic right whale acoustic signal processing. Part II. Improved decision architecture for auto-detection using multi-classifier combination methodology. IEEE Long Island Systems, Applications, and Technology Conf (LISAT) 2010:1-6

Garrison LP (2007) The big picture: modeling right whales in space and time. In: Kraus SD, Rolland R (eds) The urban whale: North Atlantic right whales at the crossroads. Harvard University Press, Cambridge, MA, p 460-487

Garson GD (2008) Univariate GLM, ANOVA, and ANCOVA. Statistical Associates Publishers, Asheboro, NC

Gillespie D (2004) Detection and classification of right whale calls using an 'edge' detector operating on a smoothed spectrogram. Can Acoust 32:39-47

Hain JHW, Ellis SL, Kenney RD, Slay CK (1999) Sightability of right whales in coastal waters of the southeastern United States with implications for the aerial monitoring program. In: Garner GW, Amstrup SC, Laake JL, Manly BFJ, McDonald LL, Robertson DG (eds) Marine mammal survey and assessment methods. A. A. Balkema, Rotterdam, p 191-208

> Holt MM, Noren DP, Emmons CK (2011) Effects of noise levels and call types on the source levels of killer whale calls. J Acoust Soc Am 130:3100-3106

Jackson KA, Pitchford TD (2010) Aerial surveys for ship strike mitigation and other field observations of North Atlantic right whales (Eubalaena glacialis) off the East Coast of Florida December 2009-April 2010. Southern Early Warning System final report. Florida Fish and Wildlife Conservation Commission, Fish and Wildlife Research Institute, Tallahassee, FL

Jackson KA, Jakush JL, Ortega-Ortiz JG (2011a) Aerial surveys for ship strike mitigation and other field observations of North Atlantic right whales (Eubalaena glacialis) off the East Coast of Florida and Georgia, December 2010-March 2011. Central Early Warning System annual report. Florida Fish and Wildlife Conservation Commis- 
sion, Fish and Wildlife Research Institute, Tallahassee, FL. http://sero.nmfs.noaa.gov/protected_resources/right_ whale/seus_sightings/index.html

Jackson KA, Jakush JL, Pitchford TD, Ortega-Ortiz JG (2011b) Aerial surveys for ship strike mitigation and other field observations of North Atlantic right whales (Eubalaena glacialis) off the East Coast of Florida December 2010-March 2011. Southern Early Warning System final report. Florida Fish and Wildlife Conservation Commission, Fish and Wildlife Research Institute, Tallahassee, FL. http://sero.nmfs.noaa.gov/protected_ resources/right_whale/seus_sightings/index.html

$>$ Johnson MP, Tyack PL (2003) A digital acoustic recording tag for measuring the response of wild marine mammals to sound. IEEE J Oceanic Eng 28:3-12

Keller CA, Ward-Geiger LI, Brooks WB, Slay CK, Taylor CR, Zoodsma BJ (2006) North Atlantic right whale distribution in relation to sea-surface temperature in the southeastern United States calving grounds. Mar Mamm Sci 22:426-445

Keller CA, Garrison L, Baumstark R, Ward-Geiger LI, Hines E (2012) Application of a habitat model to define calving habitat of the North Atlantic right whale in the southeastern United States. Endang Species Res 18:73-87

Knowlton AR, Kraus SD (2001) Mortality and serious injury of northern right whales (Eubalaena glacialis) in the western North Atlantic Ocean. J Cetacean Res Manag (Spec Issue) 2:193-208

Kraus SD, Prescott JH, Knowlton AR, Stone GS (1986) Migration and calving of right whales (Eubalaena glacialis) in the western North Atlantic. Rep Int Whal Comm Spec Issue 10:139-144

Kraus SD, Brown MW, Caswell H, Clark CW and others (2005) North Atlantic right whales in crisis. Science 309: 561-562

> Laurinolli MH, Hay AE, Desharnais F, Taggart CT (2003) Localization of North Atlantic right whale sounds in the Bay of Fundy using a sonobuoy array. Mar Mamm Sci 19: 708-723

Marine Acoustics Inc. (1997) Northern right whale monitoring project: final report. Report to the Office of Naval Research, Arlington, VA

> Marques TA, Munger L, Thomas L, Wiggins S, Hildebrand JA (2011) Estimating North Pacific right whale Eubalaena japonica density using passive acoustic cue counting. Endang Species Res 13:163-172

Matthews J, Brown S, Gillespie D, Johnson M and others (2001) Vocalisation rates of the North Atlantic right whale (Eubalaena glacialis). J Cetacean Res Manag 3: 271-282

> McKenna MF, Ross D, Wiggins SM, Hildebrand JA (2012) Underwater radiated noise from modern commercial ships. J Acoust Soc Am 131:92-103

Mellinger DK, Stafford KM, Moore SE, Munger U, Fox CG (2004) Detection of North Pacific right whale (Eubalaena japonica) calls in the Gulf of Alaska. Mar Mamm Sci 20: 872-879

> Mellinger DK, Nieukirk SL, Matsumoto H, Heimlich SL and others (2007a) Seasonal occurrence of North Atlantic right whale (Eubalaena glacialis) vocalizations at two sites on the Scotian Shelf. Mar Mamm Sci 23:856-867

Mellinger DK, Stafford KM, Moore SE, Dziak RP, Matsumoto H (2007b) Fixed passive acoustic observation methods for cetaceans. Oceanography 20:36-45

Mellinger DK, Nieukirk SL, Klinck K, Klinck H, Dziak RP,
Clapham PJ, Brandsdóttir B (2011) Confirmation of right whales near a nineteenth-century whaling ground east of southern Greenland. Biol Lett 7:411-413

Morano JL, Rice AN, Tielens JT, Estabrook BJ, Murray A, Roberts BL, Clark CW (2012) Acoustically detected yearround presence of right whales in an urbanized migration corridor. Conserv Biol 26:698-707

Munger LM, Wiggins SM, Moore SE, Hildebrand JA (2008) North Pacific right whale (Eubalaena japonica) seasonal and diel calling patterns from long-term acoustic recordings in the southeastern Bering Sea, 2000-2006. Mar Mamm Sci 24:795-814

Munger LM, Wiggins SM, Hildebrand JA (2011) North Pacific right whale up-call source levels and propagation distance on the southeastern Bering Sea shelf. J Acoust Soc Am 129:4047-4054

Mussoline SE, Risch D, Hatch LT, Weinrich MT and others (2012) Seasonal and diel variation in North Atlantic right whale up-calls: implications for management and conservation in the northwestern Atlantic Ocean. Endang Species Res 17:17-26

Naessig PJ, Taylor CR (2010) Northern early warning system North Atlantic right whale (Eubalaena glacialis): aerial surveys, 2009-2010 season. Final report to Georgia Department of Natural Resources. Wildlife Trust, St. Petersburg, FL. http://sero.nmfs.noaa.gov/protected_ resources/right_whale/seus_sightings/index.html

Naessig PJ, Taylor CR (2011) Northern early warning system North Atlantic right whale (Eubalaena glacialis): aerial surveys, 2010-2011 season. Final report to Georgia Department of Natural Resources. Ecohealth Alliance, St. Petersburg, FL. http://sero.nmfs.noaa.gov/protected_ resources/right_whale/seus_sightings/index.html

NDBC (National Data Buoy Center) (2012) www.ndbc.noaa. gov (accessed on April 12, 2012)

Oleson EM, Calambokidis J, Burgess WC, McDonald MA, LeDuc CA, Hildebrand JA (2007) Behavioral context of call production by eastern North Pacific blue whales. Mar Ecol Prog Ser 330:269-284

Parks SE, Clark CW (2007) Acoustic communication: social sounds and the potential impacts of noise. In: Kraus SD, Rolland RM (eds) The urban whale: North Atlantic right whales at the crossroads. Harvard University Press, Cambridge, MA, p 310-332

> Parks SE, Tyack PL (2005) Sound production by North Atlantic right whales (Eubalaena glacialis) in surface active groups. J Acoust Soc Am 117:3297-3306

Parks SE, Hamilton PK, Kraus SD, Tyack PL (2005) The gunshot sound produced by male North Atlantic right whales (Eubalaena glacialis) and its potential function in reproductive advertisement. Mar Mamm Sci 21:458-475

Parks SE, Urazghildiiev I, Clark CW (2009) Variability in ambient noise levels and call parameters of North Atlantic right whales in three habitat areas. J Acoust Soc Am 125:1230-1239

Parks SE, Searby A, Célérier A, Johnson MP, Nowacek DP, Tyack PL (2011) Sound production behavior of individual North Atlantic right whales: implications for passive acoustic monitoring. Endang Species Res 15:63-76

Parks SE, Hotchkin CF, Cortopassi KA, Clark CW (2012) Characteristics of gunshot sound displays by North Atlantic right whales in the Bay of Fundy. J Acoust Soc Am 131:3173-3179

Richardson W, Greene CJ, Malme C, Thomson D (1995) Marine mammals and noise. Academic Press, San Diego, CA 
Schulte DW, Taylor CR (2010) Documenting spatial and temporal distribution of North Atlantic right whales of South Carolina and northern Georgia 2009-2010. Final report to National Oceanic and Atmospheric Administration. Wildlife Trust, St. Petersburg, FL. http://sero.nmfs.noaa. gov/protected_resources/right_whale/seus_sightings/ index.html

Schulte DW, Taylor CR (2011) Documenting spatial and temporal distribution of North Atlantic right whales off South Carolina and northern Georgia 2010-2011. Final report to National Oceanic and Atmospheric Administration. Ecohealth Alliance, St. Petersburg, FL. http://sero.nmfs. noaa.gov/protected_resources/right_whale/seus_sightings/ index.html

Širović A, Hildebrand JA, Wiggins SM, McDonald MA, Moore SE, Thiele D (2004) Seasonality of blue and fin whale calls and the influence of sea lee in the Western Antarctic Peninsula. Deep-Sea Res II 51:2327-2344

Širović A, Hildebrand JA, Wiggins SM (2007) Blue and fin whale call source levels and propagation range in the Southern Ocean. J Acoust Soc Am 122:1208-1215

Spaulding E, Robbins M, Calupca T, Clark CW and others (2010) An autonomous, near-real-time buoy system for automatic detection of North Atlantic right whale calls. Proc Meetings Acoust 6:1-22

Stafford KM, Mellinger DK, Moore SE, Fox CG (2007) Seasonal variability and detection range modeling of baleen whale calls in the Gulf of Alaska, 1999-2002. J Acoust Soc Am 122:3378-3390

Taylor JKD, Zani MA, Knowlton AR, Wikgren B, Hamilton P, Kraus SD (2010) Aerial surveys to reduce ship/whale collisions in the calving ground of the North Atlantic right whale (Eubalaena glacialis). Central Early Warning System final report. New England Aquarium, Boston, MA. http://sero.nmfs.noaa.gov/protected_resources/right_ whale/seus_sightings/index.html

Urazghildiiev IR, Clark CW (2006) Acoustic detection of North Atlantic right whale contact calls using the generalized likelihood ratio test. J Acoust Soc Am 120:1956-1963

Urazghildiiev IR, Clark CW (2007) Acoustic detection of North Atlantic right whale contact calls using spectrogram-based statistics. J Acoust Soc Am 122:769-776

Urazghildiiev IR, Clark CW, Krein TP, Parks SE (2009) Detection and recognition of North Atlantic right whale contact calls in the presence of ambient noise. IEEE J Oceanic Eng 34:358-368

Urick R (1975) Principles of underwater sound. McGrawHill, New York, NY

Urick RJ, Gaunaurd GC (1972) Detection of fluctuating sonar target. US Naval Ordnance Laboratory, White

Editorial responsibility: Andrew Read,

Beaufort, North Carolina, USA
Oak, MD

> Urick RJ, Lund GR, Bradley DL (1969) Observations of fluctuation of transmitted sound in shallow water. J Acoust Soc Am 45:683-690

US Naval Observatory (2011) Astronomical Applications Department of the U.S. Naval Observatory. http://aa. usno.navy.mil. (accessed on July 30, 2011)

Van Parijs SM, Clark CW, Sousa-Lima RS, Parks SE, Rankin S, Risch D, Van Opzeeland IC (2009) Management and research applications of real-time and archival passive acoustic sensors over varying temporal and spatial scales. Mar Ecol Prog Ser 395:21-36

> Ward-Geiger LI, Silber GK, Baumstark RD, Pulfer TL (2005) Characterization of ship traffic in right whale critical habitat. Coast Manag 33:263-278

Waring GT, Josephson E, Maze-Foley K, Rosel PE (2012) US Atlantic and Gulf of Mexico marine mammal stock assessments - 2011. NOAA Tech Memo NMFS-NE-221, NOAA, NFSC, Woods Hole, MA

Watwood SL, Miller PJO, Johnson M, Madsen PT, Tyack PL (2006) Deep-diving foraging behaviour of sperm whales (Physeter macrocephalus). J Anim Ecol 75:814-825

- Welch PD (1967) The use of fast Fourier transform for the estimation of power spectra: a method based on time averaging over short, modified periodograms. IEEE Trans Audio Electroacoust 15:70-73

> Wenz GM (1962) Acoustic ambient noise in the ocean: spectra and sources. J Acoust Soc Am 34:1936-1956

Wiggins SM, Hildebrand JA (2007) High-frequency acoustic recording package (HARP) for broad-band, long-term marine mammal monitoring. In: International Symposium on Underwater Technology 2007 and International Workshop on Scientific Use of Submarine Cables \& Related Technologies 2007. Institute of Electrical and Electronics Engineers, Tokyo, p 551-557

Wiggins SM, McDonald MA, Munger LM, Moore SE, Hildebrand JA (2004) Waveguide propagation allows range estimates for North Pacific right whales in the Bering Sea. Can Acoust 32:146-154

> Wiggins SM, Roch MA, Hildebrand JA (2010) TRITON software package: analyzing large passive acoustic monitoring data sets using MATLAB. J Acoust Soc Am 128:2299

Winn HE, Price CA, Sorensen PW (1986) The distributional biology of the right whale (Eubalaena glacialis) in the western North Atlantic. Rep Int Whal Comm Spec Issue 10:129-138

Zakarauskas P (1986) Ambient noise in shallow water: a literature review. Can Acoust 14:3-17

Zar JH (1999) Biostatistical analysis. Prentice Hall, Upper Saddle River, NJ

Submitted: February 5, 2013; Accepted: March 19, 2014 Proofs received from author(s): July 25, 2014 